\title{
El origen del mundo y su dinamismo cósmico y antropológico según san Agustín
}

\author{
Prof. Dr. TARsicio JÁÑEZ BARrio \\ Universidad Católica Andrés Bello. Caracas, Venezuela
}

Recibido: 25 de junio 2021

Aceptado: 18 octubre 2021

Resumen: El artículo analiza el origen originante del mundo-cosmos, lo cual conlleva preguntarnos por un doble nivel radical. En el primer nivel, y como primer punto, se inquiere sobre el origen incausado de un cosmos y su dinamismo-vital increado. Como segundo punto, tratamos la razonabilidad de la existencia de este mundo causado-creado con el tiempo y su dinamismo vital por un ser-quien incausado, según sostiene la posición cristiana y en particular la posición agustiniana. En el segundo nivel se indaga sobre el carácter de un cosmos evolutivo como exigencia derivada de la razonabilidad de un mundo causado-creado y de su dinamismo-vital. Finalmente, se considera cómo ese dinamismo antropológico evolutivo, desde sus rationes seminales-causales, apunta a y culmina en el hombre-persona (mens): "ad imaginem Dei Trinitatis".

Palabras clave: Cosmos, Origen, Dinamismo vital, Creación, Evolución, Razón seminal

Abstract: The article analyses the originating cause of the world-cosmos, which makes us ask questions in a double-radical level. In the first level, and as the first point, the uncaused origin of a cosmos and its uncreated vital dynamism are investigated. As a second point, we deal with the rea- 
sonability of the existence of this world as caused-created within the time, and its vital dynamism as guided by a Being who is the Uncaused, a stand held by Christianity and in particular the Augustinian position. Therefore, in the second level the subject of investigation is the evolutionary character of the cosmos as an imperative derived from the reasonability of a caused-created world and its vital-dynamism. The final discussion treats how this evolutionary anthropological dynamism, from its rationes seminales-causales, leads to and culminates in the man-person (mens): «ad imaginem Dei Trinitatis».

Key words: Cosmos, Origin, Vital Dynamism, Creation, Evolution, Seminal Reason

\section{Introducción: Dios, origen originante del mundo cuyo dinamismo vital-evolutivo culmina en el hombre-persona (mens)}

La pregunta radical que se hace todo hombre de "corazón inquieto": ¿por qué existe el mundo y no más bien la nada? ¿Por qué ha de tener una causa y un sentido razonable? ¿Por qué nuestra inquietud racional se hace preguntas radicales buscando la radicalidad de su sentido?... En el ámbito de estas preguntas hay que ubicar la nuestra sobre el origen del mundo y de su dinamismo cósmico y antropológico.

La pregunta sobre el origen o causa originante del cosmos busca fundamentación última, pero a sabiendas de aquella respuesta que solo puede ser razonable y no racional-científica. Las diversas respuestas racionales que la ciencia pretende dar no gozan de suficiente razonabilidad. Esta insuficiencia la podemos constatar cuando los mismos científicos afirman que el origen del cosmos tiene su incausación: en la nada y/o la materia, en algo caótico, en la necesidad y/o en azar (casualidad), o finalmente en un tiempo eterno - ab aeterno-- $\mathrm{y}$ lo hacen desde tres posiciones distintas, cuyo origen incausado (e increado) sea: * la materia y/o nada (vacío cuántico) autoimplicativas (Stephen Hawking); * sea el tiempo-eterno, con origen en el vacío cuántico (nada), ¿indefinido? (I. Prigogine); * el azar, el caos y/o la necesidad. Estas posiciones exceden el ámbito de su competencia científica, toda vez que la misma ciencia, por definición, no se ocupa de la causa o razón última y mucho menos dar por razonables e incluso, como racionales, respuestas tan irracionales como son admitir el azar y/o la necesidad, que es la manera inconfesa de ocultar la ignorancia. Razonablemente solo cabe partir 
de un existente absoluto, incausado y creador, que como tal, libremente crea, pues de lo contrario caeríamos en lo irracional que supone partir de la necesidad y/o del azar (hado). Crear implica, en sí mismo, crear desde la inteligencia, la libertad y el amor, como reza la posición cristiano-agustiniana. Por lo tanto, el origen originante del cosmos y su dinamismo vital ha de tener como su razón razonable la existencia real de un Dios incausadocreador "ex nihilo" co-temporal (espacial) (S. Agustín). No será irracional, sin embargo, admitir un mundo causado-creado, ab-aeterno, pre-temporal, aunque este no es el caso (S. Agustín - Sto. Tomás)-

Nuestra pregunta, por consiguiente, sobre el origen originante del mundo-cosmos lleva consigo preguntarnos en un doble nivel radical. En el primer nivel, y como primer punto, inquirir sobre el origen incausado de un cosmos y su dinamismo-vital increado; hacemos una reflexión conjunta de la no-razonabilidad de un cosmos increado cuyo origen sea debido, bien a la nada y/o a la materia auto-incausadas, bien al azar (al acaso), al caos y/o a la necesidad, bien a un tiempo eterno, ¿indefinido?; $y$ como segundo punto, inquirir sobre el origen de un cosmos causado-creado, tratamos la razonabilidad de la existencia de este mundo causadocreado con el tiempo y su dinamismo vital por un ser-quien incausado, según sostiene la posición cristiana, pero resaltando en particular la posición agustiniana. $Y$ en el segundo nivel, inquirir sobre el carácter de un cosmos evolutivo como exigencia derivada de la razonabilidad de un mundo causado-creado y de su dinamismo-vital, haciendo una diferenciación crítica y contrastada entre el dinamismo cósmico evolutivo de P. Laín Entralgo y el dinamismo antropológico evolutivo de S. Agustín. Para finalmente, considerar cómo ese dinamismo antropológico evolutivo, desde sus rationes seminales-causales, con "su flecha de temporalidad", apunta a y culmina en el hombre-persona (mens): "ad imaginem Dei Trinitatis".

\section{A. ORIGEN ORIGINANTE DEL COSMOS Y SU DINAMISMO VITAL}

\section{A.1. La no-razonabilidad de un cosmos incausado-increado y su dina- mismo}

El cosmos (mundo ordenado) apareció a partir de una "sopa primigenia" caótica e incausada, o materia eterna (materialismo), porque la ma- 
teria, que no puede ser creada (ser causada), en un momento indeterminado, comenzó a ordenarse debido, bien a la necesidad, bien al azar. Somos producto de la casualidad y de la necesidad (naturalismo). Según Carl Sagan, el universo sería el producto de procesos ciegos, sin un fin determinado. Pero, lo lógico sería que la sopa primigenia siendo realidad caótica y eterna, originase (emanase) una realidad igualmente caóticaconfusa-eterna, y no un cosmos. ¿Qué de razonable-creíble puede tener esta posición? Porque ¿cómo entender que esa materia -sopa primigenia, caótica- sea eterna e incausada? Admitir un mundo-material eterno-incausado, caótico (no digamos admitir la eternidad del mundo, o la eternidad como mundo), o digamos también admitir que un mundo ha salido de la nada originaria, equivale a negar la evidencia de este mundo-cosmos temporal, constitutivamente contingente y objetivo. A veces tanto cientificismo nos impide ver lo razonable de la razón. Disintiendo de esta posición cientificista decía admirado A. Einstein: "Lo más incomprensible del mundo es que sea un cosmos tan comprensible".

El modelo cosmológico que nos propone Stephen Hawking de un mundo (multiverso) material infinito, infinito a parte ante e infinito a parte post (sin fronteras), es un modo de desplazar el problema a un nivel más alto (Davies). En este modelo ¿quedaría lugar para el hombre?”, se pregunta Francisco José Soler Gil ${ }^{1}$. En ese nivel más alto, ¿dónde queda la realidad contingente de todas y de cada una de las cosas (entes), si son consideradas infinitas cuantitativa y cualitativamente? El genio de Stephen W. Hawking afirma (1942) contundente: "La materia salió de la nada a través de una separación de ella y de su contraria la antimateria”, autoimplicándose a sí misma”. Pero la nada, si es nada, ¿cómo puede producir algo lo no-algo absoluto? ¿Cómo entender que la nada sea implicativa de sí misma?. Y ¿cómo explicar razonablemente que existió en el origen primigenio la materia y su contraria la antimateria? La falta de lógica entre los datos que Hawking apunta, ateniéndose a la cosmología cuántica, y las consecuencias que deduce, es patente ${ }^{2}$.

${ }^{1}$ Francisco José Soler Gil, Lo divino y lo humano en el Universo de Stephen Hawking, Cristiandad, Madrid 2008, 300; Id., Mitología materialista de la ciencia, Encuentro, Madrid 2013, 285 y 294.

${ }^{2}$ Id., Mitología materialista de la ciencia, 232; 240 ss.; 261 ss. 193 ss.; Id., Lo divino y lo humano en el Universo de Stephen Hawking, 123 ss.; 154. 
Parecida incongruencia lógica encontramos en Fernando Savater al preguntarse por la ausencia de causa referida al universo y a Dios, sin especificar el sentido de "causa (causalidad): "Si vamos a aceptar que Dios no tiene causa, también podríamos haber aceptado antes que el universo

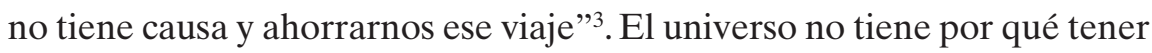
una causa, porque no es un objeto de la experiencia, decían Kant - B. Russell. Pero resulta que el universo sí es un objeto de experiencia. Luego necesita tener una causa: "En cualquiera de los modelos del universo que se barajan en la cosmología física, se puede mostrar que el universo presenta los rasgos esenciales de un objeto ordinario. De lo que se deduce, que es legítimo y razonable esperar que tenga una causa", "puesto que todo objeto físico posee una causa" ${ }^{4}$. El sentido materialista les ciega para captar el sentido de la lógica, tanto a S. Hawking como a Fernando Savater, según, muy acertadamente desvela F.J. Soler5: "Aceptado el sentido del universo que propone Fernando Savater como el conjunto indeterminado e indeterminable de las cosas, rechazará la pregunta por la causa del universo y la idea de un orden racional cósmico. Ahora bien, es evidente que la idea de universo asociada con el pensamiento materialista, implica la negación de la mera posibilidad de la cosmología como ciencia. Pues afirmar que el universo no es una totalidad nítidamente perfilada..., equivale a decir que no es un objeto físico. Puesto que si la realidad fundante es la materia, lo más coherente es sostener que no puede haber ciencia del universo como un todo, mientras que si la realidad fundante es el Dios racional del teísmo, lo más coherente es suponer que el universo, en tanto que creado, es una realidad inteligible y de rasgos determinados..."6. Entonces

${ }^{3}$ Fernando Savater, Las Preguntas de la Vida, Ariel, Barcelona 1999, 131-134. Lo ilógico de su argumento es poner en pie de igual, a priori, a Dios y a la materia. ¿Por qué hacer de la materia una divinidad y negar a Dios? Y si la materia, el mundo no tiene una causa ¿por qué razón buscar razones y relaciones causales en los fenómenos de la naturaleza? Lo lógico sería negar todo tipo de razonamiento y de búsqueda científica. Que equivaldría a negar la racionalidad humana. Y precisamente como los modelos cosmológicos actuales nos llevan a afirmar que el mundo tiene una causa. Luego hemos de buscarla fuera del propio mundo. Y nos queda otro recurso que acudir a la realidad sustentante de Dios.

${ }^{4}$ F.J. Soler Gil, Mitología materialistas de la ciencia, 235 ss.; Ibíd. 238.

${ }^{5}$ Id., Lo divino y lo humano en el Universo de Stephen Hawking, 23; cf. Id., Mitología materialista de la ciencia, 233.

${ }^{6}$ Id., Lo divino y lo humano en el Universo de Stephen Hawking, 154 ss. 
lo más coherente y razonable es negar que la materia sea una realidad fundante (materialismo) según la cual no puede haber una cosmología como ciencia del universo, y afirmar que existe el universo porque tiene una causa o razón de existir, "causa primera, fundamentante y trascendental de toda realidad", la cual es muy distinta del mismo universo (teísmo), tanto si es un todo considerado como mayor que la suma de sus componentes, como si es mero conglomerado de partes?

\section{a. La nada-vacío cuántico- y/o la materia auto-incausadas originan el mundo}

La concepción materialista pareciera "gozarse en doctrinas insostenibles en la medida que con más abundancia y riqueza hablan a favor de un marco teísta los datos científicos" ", porque negar que exista una razón o causa de la existencia del universo implica negar la pregunta misma por la causa del universo y la idea de un orden racional cósmico9. "La materia se comprende a sí misma, el mundo se comprende a sí mismo. No hay por qué apelar a trascendentalismo alguno", afirma Martín López Corredoira ${ }^{10}$. Pero le rebate, F. Soler Gil,--después de hacer un recorrido crítico sobre la concepción materialista-: "Lo más plausible es admitir que la materia no se basta a sí misma, sino que está apuntando hacia otra realidad que fundamenta su existencia y su modo de ser. Esa realidad es Dios. Y el universo es la obra de arte de Dios"11. Si el universo no tiene por qué tener una causa, entonces, ¿por qué pretender explicarnos el mundo y hacer ciencia, y al mismo tiempo, en nombre de la ciencia, inventar, sin razón suficiente alguna, el azar o la necesidad como origen-causa del mundo? $\mathrm{Y}$ ¿por qué rechazar a los que buscamos causas o razones que no tengan aquellas incongruencias, cuando la búsqueda del saber razonable y racional está ínsita en la constitución humana, sin la cual el hombre no sería hombre? "Omnes homines scire desiderant" (Aristóteles).

${ }^{7}$ Manuel Cabada Castro, El Dios que da que pensar. Acceso filosófico-antropológico a la divinidad, BAC, Madrid 1999, 61 ss.; Ibíd.91-93.

${ }^{8}$ F.J. Soler Gil - Martín López Corredoira, ¿Dios o la Materia? Un debate sobre cosmología, ciencia y religión, Áltera, Barcelona 2008, 32; Ibíd. 89 ss.

${ }^{9}$ Ibíd. 19 ss.; Id., Lo divino y lo humano en el Universo de Stephen Hawking, 154 ss.

${ }^{10}$ F.J. Soler Gil-Martín López Corredoira, o.c. 287 ss.

${ }^{11}$ Ibíd. 90. 
Pero si el mundo no tiene una causa o porqué, ¿por qué inventar que se auto-implica, se auto-causa a sí mismo? Y si se refieren a que no tiene por qué tener una causa más allá de sí mismo (sobre sí mismo), ¿cómo es que este mundo (multiverso incluido, autoimplicado) es contingente? Nos quedaría sólo el recurso -injustificado- a una sucesión infinita de causas que equivaldría a no tener causa (la serie de causa hasta el infinito es absurdo; es el pez que se muerde la cola), o a que cada una fuera causa de sí misma, con lo cual volveríamos a un mundo auto-implicado. Y entonces persiste la pregunta: ¿Cómo una realidad fundante puede ser contingente, en constante cambio dinámico, y en la misma medida ser causa de sí misma? O tendríamos que entender "causa de otra manera"? Y por tanto, tendríamos que construir, también de otra manera, nuestra argumentación..." Pero admitir la sucesión infinita de causas no eliminaría en ningún momento la objetualidad del todo y por ende la necesidad de causa en otro nivel"12.Y como la causa es distinta y superior a lo causado, no es comprensible recurrir a una serie infinita de causas, porque entonces tendríamos el absurdo de que lo superior y distinto no sería ni superior ni distinto, sino que sería igual. $\mathrm{O}$ admitir, contra toda racionalidad, que constitutivamente una misma realidad pueda ser causa y efecto de sí misma, "in eodem sensu".

Por tanto, en lugar de una serie infinita de causas (que sería equivalente a no explicar razonablemente que exista causa), es necesario postular una causa infinita-subsistente, y distinta de su efecto, i.e., un Dios, realidad subsistente-transcendente, absoluta, distinta y suprema ${ }^{13}$. La divinidad no se asienta en el nivel mundano. Decía Ortega y Gasset: "El Dios que tiene límites y figura,... el Dios, en suma, capaz de ser objeto para la atención, se parece como tal, demasiado a las cosas del intramundo para ser el auténtico Dios"14. Agustín gustaba de meditar: "Deus semper maior"15. Y Karl Rahner: "Al decir Dios queremos decir el "todo", pero

${ }^{12}$ F.J. Soler Gil, Mitología materialista de la ciencia, 237; Ibíd. 281 ss.

${ }^{13}$ SR 185 ss.; Id., Estructura dinámica de la realidad, 95 ss.; Laín Entralgo, Qué es el hombre, 221 ss. "La ciencia no se ocupa de causas, sino de leyes, de cómo son las cosas, cómo se nos muestran, cómo hacen lo que hacen; los "porqués" supuestamente causales que da a conocer la ciencia se refieren, no a lo que una cosa realmente es, sino a sus relaciones con otras cosas, o a la de sus partes entre sí, y no a lo que la cosa es, al qué de la cosa”.

${ }^{14}$ J. Ortega y Gasset, Origen y epílogo de la filosofía, Espasa-Calpe, Madrid 1980,111.

15 Doctr. chr. 1,7,7. 
no como la suma de los fenómenos, sino el "todo" en su fundamento fundamentante y origen inalcanzable, que está por encima, por detrás y por delante..."16. "Deus interior intimo meo et superior summo meo"17.

\section{b. El tiempo eterno, ¿origen indefinido?, vacío cuántico (Ilya Prigogine)}

En referencia a la temporalidad-eternidad del mundo, o a un tiempo eterno, Ilya Prigogine, nos cambia el baremo conceptual clásico, al admitir la eternidad del tiempo, porque en sí mismo parece una "contradictio in términis". "El tiempo es anterior a la existencia... A la historia del cosmos debemos atribuirle un tiempo anterior al nacimiento mismo de nuestro universo. Este nacimiento del mundo podría ser semejante a un cambio de fase que condujera de un pre-universo (vacío cuántico, o meta-universo) al universo observable que nos rodea...En esta perspectiva el tiempo es eterno, no tiene principio ni fin ${ }^{18}$. "La cuestión del nacimiento del tiempo y la de los orígenes seguirán planteadas. La posibilidad de que el tiempo no tenga comienzo, que sea anterior a la existencia de nuestro universo, resulta una alternativa razonable"19. Pero, Ilya Prigogine no precisa cómo puede entenderse que ese pre-universo, o vacío cuántico, sea el origen de la temporalidad-eterna de nuestro mundo, si ha de ser algo real-existente. Nos habla de una temporalidad-eterna, pero nunca de un tiempo incausado. ¿Cómo es que el vacío cuántico daría origen al tiempo?. En el sentir agustiniano "no es concebible un tiempo sin seres creados"20; "no existiría el tiempo sin no existieran las criaturas" ${ }^{1}$, pues, "el tiempo mismo es una

${ }^{16}$ Karl Rahner: Gnade als Freiheit Kleine theologische Beiträge, Herder, Freiburg. i. Br. 1968, 19. Cit. en Manuel Cabada Castro, o.c., 84.

${ }^{17}$ Conf. 3,6,11.

${ }^{18}$ Ilya Prigogine, El fin de las certidumbres, Andrés Bello, Barcelona-Santiago de Chile 1997, 179 y 183; Ib.,183. Me parece más natural que aceptar la teoría del big-bang (origen del tiempo), suponer que el nacimiento del universo es un acontecimiento en la historia del cosmos y que debemos atribuir a éste un tiempo anterior al nacimiento mismo de nuestro universo. Pero, ¿qué sucedió antes del big-bang? (Ibíd. 196). El nacimiento de nuestro universo se manifiesta por una explosión de entropía (Ibíd.199).

${ }^{19}$ Ibíd.202. La historia de la materia está engastada en la historia cosmológica, la historia de la vida en la de la materia. Y finalmente, nuestras propias vidas están sumergidas en la historia de la sociedad" (Ibíd.203). "Negar el tiempo es negar la realidad" (Ibíd.209).

${ }^{20}$ Conf. 11,30,40.

${ }^{21}$ Ciu. 11,6. 
criatura"22. Por lo demás esta concepción del tiempo de Prigogine tal vez pudiera ubicarse dentro del considerando de Agustín sobre aquel otro tiempo, pero causado: "Aquel tiempo no es este tiempo, como aquella realidad no es esta nuestra realidad: "Erat aliud tempus, quando non erat hoc tempus" ${ }^{23}$. En todo caso una realidad necesariamente causada, aunque pudiera ser "ab aeterno". Hemos de distinguir nítidamente realidad intemporal de realidad incausada, así como temporalidad de causalidad.

\section{c. El azar-la casualidad-el caos y/o la necesidad originan el cosmos}

Pero ¿no es menos absurdo aceptar el "azar” o el "caos” como algo eterno y previo a toda existencia? ¿Cómo es posible comprender que el "azar" produzca la existencia? Acaso el "azar" es un algo, o que necesariamente sea un algo? El concepto mismo de "azar" supone, en sí mismo, algo previo de lo cual resulte que tenga sentido hablar de "azar". Érase una vez en la que hubo nada y por azar o acaso, resultó algo, jtanta maravilla, prostituye la razón!. A. Einstein dice: "A igual título que el determinismo o la necesidad, el puro azar es una negación de la realidad y de nuestra exigencia de entender el mundo"24. Por igual modo i el "caos", realidad difusa-amorfa, luce razonable y admisible que sea algo incausado y creador de orden, de vida, de logos?

Quienes admiten, pues, la existencia de un mundo "ab aeterno" caótico e incausado, venido a la temporalidad por "azar" o por "acaso" (casualidad)", se quedan sin base razonable alguna. Se conforman con su recurso a la explosión universal o "big-bang”. Está bien. Pero en este momento se trata de cómo razonar el por qué previo a esa explosión. Y se dirá también por toda razón: ha venido a exigencias del mismo "azar", o del "acaso", o de la necesidad, que es dar como razón la ignorancia de la causa, pero la causa se supone siempre. ¿Es que el "azar” (hado) tiene exigencias? El "azar" o el "acaso" como punto absoluto de arranque, es ignorar el sentido o causa; y por lo mismo es atrevimiento injustificado, admitir que venimos a la temporalidad existencial por "azar". Total, todo un verdadero círculo vicioso. Así lo considera Aristóteles: "Es absurdo, el azar como causa o principio originario de la realidad. Y aceptar el "azar",

\footnotetext{
${ }^{22}$ Gen.ad litt. i.o. 3,7-8.

${ }^{23}$ Ciu. 12,15,1-3; 11,6-7; cf. Conf. 11,13,15-16; 12,9,9; 12,11-12.

24 Cit. por I. Prigogine, o.c. 209-211.
} 
el acaso (suerte, fortuna, hado, destino) en los acontecimientos de la vida, lo hacemos por ignorar la causa" 25 .

¿Por qué se admiten el "azar y/o la necesidad” conforme razón y no la causación y su vertiente teleológica? ${ }^{26}$ ¿Acaso no es, indudablemente razonable, admitir finalidad causativa en la naturaleza que obra bien según leyes físicas estables, bien por instinto (animales), bien con libertad en los procesos y acciones (hombre)? Lo que tiene un principio, la suposición razonable, es que tenga una finalidad y tienda a un fin. Todo lo que existe tiene una razón suficiente para existir. Y todo lo que opera (obra), opera por un fin. Lo que tiene una razón de existir, la tiene para un desarrollo-perfeccionamiento como fin propio. El obrar, bien como tropismo o instinto propio de los seres vivos (plantas-animales), o bien el desarrollarse del hombre con su razón y libertad, obedecen a una causa. Pero el hecho de no admitir la causa creadora, inclusive si nos dejamos llevar de la "sola razón racionalista", no puede llevarnos, en lógica elemental, a concluir: luego es obra del "azar, o del acaso, o de la necesidad". Si el azar, el acaso, el hado, el destino (fatum), la necesidad implican ignorar (tanto la causa eficiente como final), entonces ¿por qué negar la creación como causa razonable (incluso como la única razonable)? Es más, partiendo del dinamismo cósmico, ¿ cómo justificar que por un mero desarrollo evolutivo hagan su aparición en el mundo la inteligencia y la libertad, i.e., la persona-mens? Ese dinamismo cósmico ha de implicar al mismo tiempo,

${ }^{25}$ Aristóteles, Phys. II,5-8: Azar, en general lo no explicable. Tenemos dos grupos: el grupo "azar-suerte-fortuna", son conceptos distintos y hasta opuestos, al de "destino o hado", el primer grupo describe acontecimientos contingentes y el segundo acontecimientos predeterminados. Cf. Metaph. 7,9.

${ }^{26}$ P. Laín Entralgo, para defender la teleonomía y rechazar la teleología, razona así: "Porque contemplando a posteriori la serie de estructuras a que el curso de la evolución haya dado lugar, la mente del sabio podrá conjeturar, no más que conjeturar como creencia razonable, mas no afirmar como saber objetivo y racional que la evolución tiene realmente un sentido" (Ibíd. 116). ¿Es acaso así como hay que entender la teleología? Precisamente a posteriori podemos afirmar como la finalidad del proceso evolutivo, la aparición de seres inteligentes, ha tenido lugar. Además no se trata de "obtener un saber objetivo y racional", pero si afirmar razonablemente de que todo apunta hacia un fin tendencial, aunque no podamos saber con precisión cuál fin específico. Es que, ¿acaso el proceso evolutivo, que hoy nadie niega, es proceso ciego? En contra, cf. Francisco Soler Gil, ¿Dios o la Materia? Un debate sobre cosmología, ciencia y religión, 88 -90. 
y constitutivamente, un dinamismo vital-antropológico. Así lo entendieron S. Agustín y X. Zubiri ${ }^{27}$.

No es fácil entender cómo Pedro Laín E., tan en línea de X. Zubiri, ahora nos diga que el origen del cosmos es debido al azar, cuando esto implica negar la creación. A no ser que no entendamos bien la frase consignada arriba. Al hablar del origen del cosmos se detiene a considerar su estructura y no precisa cuál es y de dónde proviene su origen ${ }^{28}$. Porque ¿dónde está la lógica, el sentido racional-razonable de este autor cuando dice: No conozco la causa o razón, luego es “azar”, no hay razón? ¿No hay razón o más bien la ignoro? Pero, además, si la causa me es desconocida ¿por qué y cómo puedo defender la "necesidad" como proceso evolutivo? ¿Por qué paladinamente confieso, más bien, que es obra también del azar? O es que ¿tal vez la teoría de la evolución conoce todas y cada una de sus etapas evolutivas y es capaz de demostrarnos con razones constatables y contrastables? "A igual título que el determinismo, el puro azar es una negación de la realidad y de nuestra exigencia de entender el mundo" 29. Luego no es razonable, i.e., no es conforme a razón.

¿No sería más razonable y sensato, confesar que debe haber alguna causa o razón dinámica interna-externa que se nos escapa? Lo razonable es obligarnos a confesar una "docta ignorantia", antes que enarbolar la soberbia "ignorantia docta". Dios realidad suprema es origen y razón de ser de lo creado, porque la aceptación de la teoría del "azar", como principio absoluto de origen, es el encubrimiento de esa ignorancia docta, como ya constatara M.T. Cicerón ${ }^{30}$. En fin: “Aliquando etiam bonus dormitat Homerus", porque Horacio "no toleraba el sestear de Homero"31.

A. Einstein en carta a Max Born, escribía en 1924 que si tuviera que abandonar la estricta causalidad preferiría "ser zapatero, incluso ser empleado de un garito, antes que ser físico". Einstein se negaba por igual a aceptar únicamente que el azar pueda ser la respuesta a nuestros interrogantes. "Lo que hoy emerge, continúa diciendo Prigogine, es, por lo tanto, una descripción

${ }^{27}$ EDR 211 ss.; 311 ss.

${ }^{28}$ Cf. HD 115 ss.; SR 142 ss.; Ibíd. 169 y 179; 217.

${ }^{29}$ Ylya Prigogine, o.c. 209; 211.

${ }^{30}$ Cf. Scott Hahn - Benjamin Wiker, Dawkins en observación. Una crítica al nuevo ateísmo, Rialp, Madrid 2011, 38 ss.

${ }^{31}$ Quintus Horatius Flaccus, Ep. Ad Pisones, Cátedra, Madrid 2000, 360. 
mediatriz, situada entre dos representaciones alienantes: la de un mundo determinista y la de un mundo arbitrario sometido únicamente al azar. Las leyes deterministas no gobiernan el mundo, pero éste tampoco se rige por el azar" 32 . Para M. de Unamuno aceptar la realidad como producto del azar y/o la necesidad es una tragicomedia, y para M. Heidegger, admitida al modo nietzscheano, traería "la destrucción de la metafísica occidental". Y apostilla Agustín: "Locos son, Señor, los que dicen que obraste por necesidad"33.

Cosa distinta será cómo explicar el proceso de ese cosmos "desde el minuto uno siguiente a la explosión del "big-bang", asunto que incumbe explicar a la ciencia ${ }^{34}$. Apostilla al respecto Laín Entralgo: "En la estructura del proceso cósmico de la evolución, se combinan el azar, la necesidad y la teleonomía"35. Y concluye su razonamiento, este prestigioso pensador: "Porque el "azar", atenido el considerador no más que a su inteligencia, sólo como un imprevisible azar puede ver la aparición en el cosmos de una estructura nueva" ${ }^{36}$.

\section{A.2. La razonabilidad del cosmos causado-creado y de su dinamismo vital}

Toda esta reflexión ha de tener necesariamente otro punto de partida distinto al materialista y cientificista. Afirma Zubiri :"La estructura del Universo es, en y por sí mismo, constitutivamente dinámica"37. Dinamismo que es un "darse de sí" originario, y no materia y energía ${ }^{38}$, como la entiende la física. Sin embargo, ese "dar de sí" es constitutivo de "materia informe con

${ }^{32}$ Ibíd. 211.

${ }^{33}$ Conf. 13,30,45.

${ }^{34}$ Tarsicio Jáñez B., Metodología de la Investigación en Derecho. Una orientación metódica, Ucab, Caracas 2008, 50 ss.

${ }^{35}$ Pedro Laín Entralgo, Qué es el hombre. Evolución y sentido de la vida, Nobel, Oviedo 1999, 115 ss. La salida es clara, "ir por los cerros de Úbeda", ni azar, ni necesidad, ni mezcla de una y de otra. Y la teleonomía, porque sólo se podrá conjeturar una creencia razonable, nunca un saber objetivo y racional, que la evolución tiene realmente un sentido. ¿Es que la teleología defiende un saber racional y objetivo sobre la evolución? Pero, entonces, no entendemos, por qué en este estudio el autor defiende la evolución. "La filosofía es la ciencia de la relación de todo conocimiento con los fines de razón humana, teleología rationis humanae" (I. Kant).

${ }^{36}$ Ibíd.

${ }^{37}$ EDR 119.

${ }^{38}$ P. Laín Entralgo, o.c. 185-186. 
su razón seminal". Cuando Teilhard de Chardin saluda a la materia como "inagotable capacidad de ser y devenir", ¿entiende materia como la entiende el materialista, o más bien como Zubiri (materista), Ortega y como Agustín, constituida conjuntamente de razón vital-causal?. La realidad originaria es materia preñada de dinamismo vital, no sólo materia (corporal, sensorial). Hoy no es admisible la concepción materialista de materia ${ }^{39}$.

Sin embargo, la eternidad de un mundo causado no excluye aceptarlo "caótico, informe", desde el cual partir para entender el advenimiento, temporal y contingente de nuestro mundo, haciéndose cosmos, según, S. Agustín, Sto. Tomás... Eterno o no, pero causado: sempiternidad-eviternidad (espíritus puros), porque una materia eterna o mundo material eterno-incausado, es irracional, pero no lo sería admitir la eternidad de un mundo causado ${ }^{40}$. Pero, al menos considerado a parte post, el mundo ha sido creado-causado "simul" con el tiempo (S. Agustín) ${ }^{41}$, pues el tiempo entra también en la categoría de "criatura"42, y "no puede haber ningún tiempo sin criatura"43.

"Ex nihilo nihil fit" rezaba, cual apotegma, la razón griega, por tanto la materia (mundo) es eterna, porque de otro modo caería en el absurdo de su procedencia "ex nihilo". La falacia griega consiste precisamente en admitir como inconcuso apotegma la eternidad del mundo: Como evidentemente "ex nihilo nihil fit", y como efectivamente existe la materia (mundo), ergo la materia (mundo) es eterna. Es esta premisa mayor la que le ha servido al clásico de base racional. Pero ¿por qué, o en virtud de qué razonable criterio, partir de un mundo material, que evidencia contingencia-defectibilidad-ca-

${ }^{39}$ Ibíd. 182. Cf. EDR 175 ss.; SH 54 ss.; SH 457; F.J. Soler Gil, ¿Dios o la Materia? Un debate sobre cosmología, ciencia y religión, 19 ss.; Ibíd. 31 ss.; F.J. Soler Gil, Mitología materialista de la ciencia, 294-295. Materia, entendida al modo de Agustín, Teilhard de Chardin, o de Zubiri, no se opone a espíritu, sí a corpóreo (materia inerte, pasividad pura).

${ }^{40}$ Sto. Tomás: "No puede demostrarse la eternidad del mundo, ni su no eternidad". I. Kant: "Puede probarse tanto la eternidad del mundo como la no eternidad". Asunto teórico, que no inquietaba a S. Agustín. Para él era claro el razonamiento: El mundo ha sido causado y creado con el tiempo (temporal), por ende, contingente, mudable, aunque podría admitirse la eternidad del mundo, pero siempre sería un mundo causado (Ciu. 11,4-6). Admitir especialmente que el alma es "coeterna a Dios", no alcanzo a ver cómo se puede explicar de modo consistente de dónde le ha venido la nueva miseria que nunca antes tuvo eternamente (Ibíd.11,4,2).

${ }^{41}$ Cf. Tarsicio Jáñez B., San Agustín frente a Darwin: Creacionismo evolutivo de "las razones seminales”, Apuntes filosóficos de la Escuela de Filosofía, UCV, Caracas 2009, 13-18.

${ }^{42}$ Gen. litt. o. $i, 3,8$.

${ }^{43}$ Conf. 10,30,40. 
rencia, ha de ser eterno y eternamente consistente? Naturalmente se cobijan en el subterfugio del "eterno retorno", algo así como una temporalidad circular repetitiva, permanente y determinista. Porque no es más que un subterfugio, porque volvemos al origen de la pregunta ¿cuál es la base de un "retornar eterno" sino de algo que se admite que es eterno y eternamente cambiante? El griego lo elevó a categoría filosófica tomándolo de los cambios naturales y cíclicos de la naturaleza. "Y no supo negar a Parménides, sin destruir a Heráclito". Hizo una inferencia totalmente ilógica, universalizó una inducción, la cual, por definición, partiendo de lo particular y mudable, concluye de modo inconsecuente, un universal inmutable.

Hoy algunos científicos que, haciendo caso omiso de la causa originaria que se busca, lo explican todo más bien como "expansión y condensación de la materia", para quienes la materia tiene existencia previa. Otra salida por la tangente. Porque, y de esta materia, ¿qué decir? ¿Es eterna la materia e incausada? Queda ya dicho la "no-razonabilidad de toda tesis materialista. Luce, por tanto, razonable -más razonable-admitir un alguien previo a este mundo material-mudable, que lo haya originado-causado con una dirección proyectiva y según la "flecha de la temporalidad", nos diría Prigogine ${ }^{44}$. Por lo mismo sigue siendo verdad que "ex nihilo nihil fit", pero suponiendo que no haya alguien previo que lo haga posible. Pero ¿acaso no es más razonable aceptar que el mundo creado procede "ex nihilo", partiendo de un alguien previo-necesario que dé existencia y consistencia a lo no existente?

Las más de las veces, los argumentos adolecen de incongruencia por no admitir ese quién previo, admitiendo, sin embargo y contra toda razón, como previos, la materia, la nada, el caos... la necesidad. ¿Por qué? Sencillamente porque se mezclan y confunden el efecto, o lo puesto de la acción, como realidad originaria, con la causa que lo origina. Por eso, en la pregunta que hemos formulado hay que distinguir, pues, el efecto originario de la causa radical formal o acción misma causativa, dinamismo radical-vital que ha hecho posible esta realidad material dinámica co-temporal (Agustín). Aquí yace el punto discriminante de la posición cristiano-agustiniana.

X.Zubiri habla en estos términos: "La causalidad es en la causa, pues, el éxtasis de la realidad en cuanto tal éxtasis -dinamismo extático-, es

${ }^{44}$ I. Prigogine, o.c. 113; Ibíd.182. El futuro ya no está dado, se convierte en una "construcción" (Paul Valéry) (Ibíd.116). 
constitutivamente éxtasis subsistente, constituye la causalidad de la causa. Porque la ciencia no ve las cosas más que desde el punto de vista del efecto" 45 . "La aparición de un efecto, por ej., el sonido de una campana, depende de otra realidad en tanto que realidad. Justo esa es la idea de causalidad". La causa no es sólo el antecedente, sino que, en la medida en que es un antecedente causal, en esa misma medida es algo no solo anterior sino superior en rango a su efecto ${ }^{46}$.

La causa formal originaria de la creación, según S. Agustín, la encontramos razonablemente expresada en los textos bíblicos: "En el principio creó Dios el cielo y la tierra. La tierra era algo caótico (informe-invisible: aóratos) y vacío (sin apariencia: akataskeúastos), y tinieblas cubrían la superficie del abismo -tohu wabohu-, mientras el espíritu de Dios aleteaba sobre la superficie (faz) de las aguas" (Gén. 1,1-3). Las cosas salen de la nada "ex nihilo"-"de nihilo", ante la llamada de Dios en orden creciente de dignidad: "Hagamos al hombre a nuestra imagen conforme a nuestra semejanza"."En el principio existía la Palabra (Verbo). Todo se hizo por Ella. En Ella estaba la vida y la vida era la luz de los hombres" (S. Juan, Ev.1,1-4).

En el principio era el Verbo... logos-razón-palabra, el amor (Dios es amor), la vida, la acción. El poder-querer-amor ontológico, como principio causativo, realiza el estatuto originario del ser, su presencia y su potencia, con su doble dimensión, ontológica y antropológica: Ergo, "ex nihilo fit ens creatum"; incluso, “de nihilo", i.e., ex eo quod omnino non est...", precisará Agustín ${ }^{47}$. Y, "volo, ergo sum” ${ }^{88}$ (S. Agustín - M. Scheler); "Voluit, ergo fecit"49 (S. Agustín).

${ }^{45}$ SR 178 ss.

${ }^{46}$ SR $173 ; 181 ; 177$.

${ }^{47}$ PTHC 154. Agustín, común y preferentemente usa la expresión "ex nihilo" (ex eo quod omnino non est), pero también, alguna vez, "de nihilo" (Nat. b. 1 y 10; 26-27; Conf. 12,7,7; 13,33,48. A Orosio: C. Prisc. 2-3), aunque aclara la diferencia en De Nat. boni, 27: La expresión "ex ipso" no significa lo mismo que "de ipso". Pues, lo que es "de ipso", puede decirse que es "ex ipso", mas no todo lo que es "ex ipso", se dice rectamente que es "de ipso". "Ex ipso enim caelum et terra, quia ipse fecit ea; non autem de ipso, quia non de substantia sua" (I.ibíd.). Por eso propiamente, dado que el "nihil" no tiene realidad ontológica alguna, le conviene tanto "ex nihilo" como "de nihilo".

${ }^{48}$ Ramiro Flórez, Presencia de la verdad, Avgvstinvs, Madrid 1971, 163; cf. Mor. 1,17,31; Gn. adu. Man. 1,2,4; Gen. litt, 1,8,14; Conf. 13,4,5: “...sed ex plenitudine bonitatis tuae”.

${ }^{49}$ A Orosio c. priscil. et orig. 3,3: “...quia voluit fecit”; Gn. adu. Man. 1,2,4: "Quare fecit Deus...? Quia voluit”; cf. Ench.9,3 


\section{A.3. La específica razonabilidad agustiniana: EI universo creado, diná- mico-vital y evolutivo en sus razones seminales-causales}

Si la ciencia sólo atiende al efecto no a la causa originaria que lo produce, la filosofía-antropológica, sin embargo, se pregunta inevitable y prioritariamente por la causa u origen originante de las cosas y su efecto. Preocupación constante de la filosofía antropológica agustiniana es atender a la causa referida al hecho creador en general y, en particular a la creación del hombre, según queda dicho. Porque en la creación como tal, i.e., como creación ex nihilo causada por un Creador participa de su potencia y perfecciones, y de la nada de que procede. Esta doble condición constitutiva hace que toda naturaleza creada en conjunto y cada cosa en particular, plasmen su participación en el Ser-Verdad-Bondad del Creador; y testifiquen al mismo tiempo la nada de su origen, de su procedencia de la nada (del no-ser). "Es grande y poco común transcender con la intención de la mente todas las criaturas de la creación que se presentan mudables y llegar a la substancia inmutable de Dios, aprender allí de su magisterio que toda naturaleza que no es lo que Él, no tiene otro autor que Él" 50 .

"Sólo hay un bien simple, y por eso único e inmutable, que es Dios. Por este bien fueron creados todos los bienes, pero no simples, y por tanto mutables" " "Él, permaneciendo en Sí, todo lo que es hecho por Él lo vuelve otra vez hacia sí, para que toda criatura tenga en sí misma el término propio de su naturaleza, por cuyo término no es lo que es Él; sin embargo, en Él halla el lugar del descanso, por el que conserva lo que ella es" 52 . Caso particular es la creación del hombre, por ser creado "a imagen y semejanza de Dios, siendo mudable y no simple, participa, sin embargo, en su medida de la inmortalidad por su alma racional ${ }^{53}$. "Nada más poderoso, nada más sublime que esa criatura a la que se llama alma racional ${ }^{54}$. Cualquier cosa que hay sobre ésa, es ya el Creador" 55 .

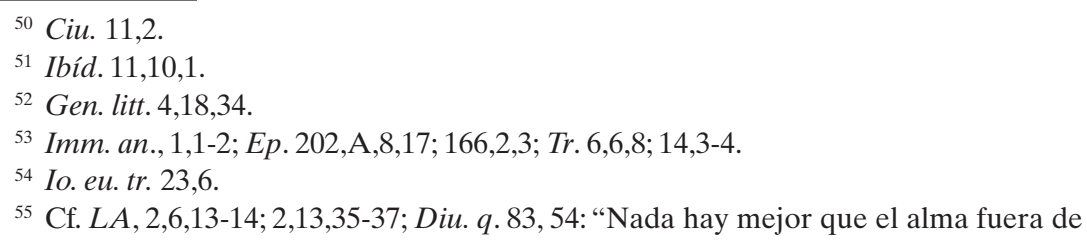
Dios". 


\section{A.3.a. Sentido agustiniano de la creación evolutiva: triple basamento específico}

Crear, en sentido específico agustiniano, es llamar a la existencia desde la nada a un mundo-universo dinámico y vital en proceso hacia un cosmos. El mundo se va haciendo cosmos por la participación en el SerVerdad-Bondad (Belleza) del Creador que incrustó su dinamismo en las razones seminales-causales. El Creador o causa originante llama al ser de la existencia desde la nada, desde lo que no es. Y así tenemos la dualidad ontológica: tender al Ser, tener ansias de ser más mejor, y declinar hacia la nada, hacia la defección en el ser ${ }^{56}$, caracterizándose la antropología agustiniana por su inquietud tensional, cuyo sentido descansa en la unidad de un triple principio ontológico-antropológico-axiológico:

\section{a.1. El principio fundamental de la ontología agustiniana}

Está conformado por el constituyente ternario de los seres creados: modus-unitas, species-forma, ordo-amor pondus ${ }^{57}$. Estos constituyentes, cual vestigios trinitarios son reveladores de su causa transcendente, de su Creador, "quien ha puesto sus límites y términos a los seres. Toda criatura tiene en sí su propio límite natural, por el que no es lo que es su Creador", dice Victorino Capánaga ${ }^{58}$, por lo que se diferencian de su causa originante: simplicidad-inmutabilidad-eternidad; mientras que todo ser creado está constituido de "complejidad (materia-forma), mutabilidad (contingencia), y temporalidad (sucesión-transitoriedad)", y por el que, dada la infinita variedad de cada criatura y la congruencia de sus partes con el todo del universo, embellecen el cosmos" ${ }^{59}$.

\section{b. El principio específico de la antropología agustiniana}

Está conformado, a su vez, por el constituyente trinitario: "mens amor et notitia eius", o mejor, "memoria-intellectus, et voluntas (amor)", donde constata que la persona humana ha sido hecha "ad imaginem Dei Trinitatis". Esta realidad antropológica hace a la persona-mens, "Deo esse pro-

\footnotetext{
${ }^{56}$ Cf. Conf. 4, 10,15.

${ }_{57}$ Tr. 6, 10.12; 8,10,14; Diu. q. 83, 68; Ciu. 19,13,1-2; . 22,28; Conf. 13,9,10.

${ }^{58}$ V. Capánaga, "Introducción General”, en: Obras completas de San Agustín Vol. I,
} BAC, Madrid 1979, 51.

${ }^{59}$ Ep. 3,4-5 -a Nebridio-; Ciu. 22,19,2; cf. Vera rel.32,59-60. 
pinquius" "Tan próxima a Dios que "en Dios somos, nos movemos y existimos". "Dios, nada existe sobre Ti, nada sin Ti. Dios, todo se halla bajo tu imperio, todo está en Ti; todo está contigo. Tú creaste al hombre a tu imagen y semejanza, como lo reconoce todo el que se conoce a sí ${ }^{61}$. "Nada sería yo, Dios mío, nada sería yo, si Tú no estuvieses en mí; pero mejor sería decir que yo no sería en modo alguno si no estuviese en Ti. Así es, Señor, así es" ${ }^{\prime 2}$.

\section{c. El principio axiológico de buena ordenación: el "ordo amoris"}

"El orden (axiológico) jerárquico de la creación -diversidad de las cosas creadas-, está escalonado por grados de tal modo que discurra desde lo más excelso hasta lo más ínfimo, por grados tan atinados que todo el que lo vea con buenos ojos comprende que debería ser así". "Jerarquía de los seres creados según la gradación (orden) por participación de la naturaleza (orden ontológico), o según el uso o estimación de cada ser humano, orden antropológico vital-existencial" ${ }^{63}$. Todo priorizado por el peso del amor. El orden del amor es el orden de la suprema ordenación jerárquica $^{64}$. "Ordo dilectionis: Vive justa y santamente el que estime en su valor toda las cosas. Este será el que tenga el amor ordenado (ordinatam dilectionem)" $" 65$.

\section{A.3.b. Correspondencia con la triple relación causal: eficiente-ejemplar- final}

La triple relación causal de las criaturas delata su origen existencial con respecto al Creador: causa eficiente, ejemplar y final. Hay correspondencia estructural trinitaria con el principio ontológico-antropológicoaxiológico. "En toda criatura, una cosa es aquello de que consta, otra lo que la discrimina de las demás, y otra lo que la hace conveniente". "No hay naturaleza alguna, y en absoluto sustancia alguna, que no contenga

${ }^{60}$ Beata $u .1,4$ : “...nam id est unum in rebus proximum Deo"; An. quant. 34,77: "nihil inter omnia quae creavit, Deo esse propinquius"; Ciu. 11,26.

${ }^{61}$ Sol. 1,1,4.

${ }^{62}$ Conf. $1,2,2 ; 1,3,3 ; 3,6,11 ; 7,1,2 ; 7,10,16 ; 7,11,17 ; 7,15,21 ; 10,7,11 ; 10,26-27 ; 13,2,2 ; 13,4,5 ;$ Tr. 6,10,11;15,6,10 -todo el libro octavo-; En. Ev. Io. 2,10.

${ }^{63}$ Lib. arb., 3,9,24; Ciu. 11,16.

${ }^{64}$ Conf. 13,9,10; Ciu. 19,13.14; $19,24$.

${ }^{65}$ Doctr. chr. 27,28. 
en sí y no presente estos tres elementos: primero el ser; después, el ser esto o lo otro; y tercero, en mantenerse en cuanto pueda en ese su ser. El primero revela la causa misma de la naturaleza; el segundo revela la especie, por la que son fabricadas y en cierto modo son formadas todas las cosas; y el tercero revela una cierta permanencia, por así decirlo en que están todas las cosas" $"$.

De la triple condición de los seres creados, "complejidad, mutabilidad y temporalidad", i.e., de su contingencia nace el dinamismo de su evolución existencial, "porque las cosas nacen y mueren, crecen hasta su perfeccionamiento y cuando son perfectas, envejecen y perecen... Sic est modus eorum "67. Pero por su participación en el dinamismo del Creador cuyo Espíritu aletea sobre todo lo creado en forma de "razones seminales-causales" comenzó el dinamismo vital que caracteriza la concepción evolutiva agustiniana. Porque las razones seminales, ínsitas en toda naturaleza creada, son verdaderas causas activas, si bien segundas, que marcan y dan sentido al verdadero proceso evolutivo.

Pero, dada la frecuente interpretación de agustinólogos que no admiten que Agustín pueda ser interpretado dentro de una verdadera y moderna concepción evolutiva, vamos a exponer, al respecto, algunos de sus principales textos y que cada cual discierna, ateniéndose no tanto al sentido literal (literalista) cuanto a su sentido real dentro del todo mental de Agustín. Porque creo que una oportuna interpretación hermenéutica, histórico efectual ${ }^{68}$, desprejuiciada, lo merece ${ }^{69}$.

${ }^{66}$ Ep. 11,3; 4: “Toda realidad obedece a una causa trina: por qué es, por qué es tal, y por qué coincide consigo. Y por tanto cuando se busca la verdad, no puede haber más que tres géneros de cuestiones: si en verdad es, si es tal o cual, y si debe ser aprobado o reprobado" (Diu. q. 83,18; q. 19). Cf. Vera rel. 7,13: "Toda cosa o sustancia, o esencia, o naturaleza, o llámese con otro nombre más adecuado, reúne al mismo tiempo estas tres cosas: que es algo único, que difiere por su forma de los demás, y que está dentro del orden universal"). Conf. $10,10,17 ; 10,40,65$.

${ }^{67}$ Conf. 4,10,15.

${ }^{68}$ Hans-Georg Gadamer, Verdad y Método. Fundamentos de una hermenéutica filosófica, Sígueme, Salamanca 1977, 370 ss.

${ }^{69}$ Excluimos evidentemente el evolucionismo darwiniano materialista, pues no goza de un verdadero evolucionismo, primero por su concepto de materia y segundo por la función que atribuye a la "selección natural". Queda ya criticado en páginas anteriores y en nuestro Estudio: "San Agustín frente a Darwin: Creacionismo evolutivo de las razones se- 


\section{A.3.c. La "vis seminal pluri-potente" causa del dinamismo evolutivo}

Dios al crear aquella "nebulosa o materia informe" la creó incubando en ella su Espíritu, i.e., plasmó "simul" su Espíritu en forma de "vis seminal pluri-potente". Según la concepción dinámica que Agustín tiene del universo creado, las razones seminales-causales" se expresan en él con los calificativos más diversos a tenor de la compleja y plural funcionalidad de su propia "vis": "primordialiter et originaliter"70, "potentialiter"71, "in prima condicione factae fuerant" non facta" 73 " "quia inerant iam ipsae numerosae rationes incorporaliter corporeis rebus intextae" 74 . Una cosa son las semillas sensibles de cuyo desarrollo surgen plantas y animales, y otra muy distinta las semillas ocultas de estas semilla:"alia vero illa oculta istorum seminum semina" "Af. "Aquellas semillas ocultas son causa de éstas visibles: "verumtamen, ante omnia visibilia semina sunt illae causae" 76 . Así "las razones seminales" o energías latentes que se engloban bajo el título de "energía" o fuerza interior, o virtud y potencia causal, predisponen a una cosa para su devenir ${ }^{77}$. Este dinamismo o potencia (vis) vital siempre la intuimos o podemos conjeturar por la razón, porque nunca brotarían de la tierra si no existiera esa misteriosa virtud ${ }^{78}$.

"El comienzo del mundo" configura el instante único en el que toda la creación salió de las manos providentes de Dios, "in ictu creavit omnia simul" (Eccl. 18,1). Es machacona la insistencia de Agustín: "Dios creó todas las cosas en su género "simul" en el principio con sus semillas (gérmenes causales, seminum semina). Dios crea las naturalezas en sus causas y éstas sin prejuicio de la actividad providente, van desarrollándose con dinamismo propio según su género distinguiéndose de otros de la misma

minales", Apuntes filosóficos, Escuela de Filosofía, UCV. Caracas 2009, 35. Cf. Rémy Chauvin, Darwinismo. El Fin de un Mito. Espasa Calpe, Madrid 2000; Francisco José Soler Gil, Mitología Materialista de la Ciencia. Encuentro, Madrid 2013.

${ }^{70}$ Gen. litt. 5,5,10.

${ }^{71}$ Ibíd. 5,5,14.

${ }^{72}$ Ibíd. 5,4,11.

${ }^{73}$ Ibíd. 6,6,10.

${ }^{74}$ Ibíd. 4,33,52.

${ }^{75} \operatorname{Tr} .3,8,13$.

${ }^{76}$ Gen. litt. 6,6,11.

77 Ibíd. 5,23,44-45.

${ }^{78}$ Tr. 3,8,13; cf. Gen. litt. 5,22,43; 5,23,44-45. 
especie $^{79}$. Las razones seminales agustinianas "racionales con actividad causativa propia y verdadera, no son fuerzas ciegas ni pasivas ${ }^{80}$. Pues de no existir en los elementos de la naturaleza esta misteriosa virtud o fuerza causal y no darse las circunstancias propicias de tiempo y lugar, no brotaría en la tierra lo que en ella no se ha sembrado. Y recurrir a la mutación aleatoria es una manera de ignorar la verdadera dinámica causal. Hay real interacción Creador-criatura, pero entendida desde el dinamismo interno originario, donde se conjugan las compatibilidades, por un lado de la acción providente "íntima y suma" sobre cada naturaleza, y por otro, de la capacidad natural intrínseca de cada naturaleza. No podemos admitir en Agustín un providencialismo que minusvalore la acción de las causas segundas (raciones seminales). Todos los seres han sido creados en una contextura proto-plasmática integrada por las razones protozoicas latentes en los gérmenes que les basta encontrar un ambiente propicio para desarrollarse, manifestarse ${ }^{81}$.

Si el evolucionismo defiende que, sobre la base del mero dinamismo cósmico, es la "selección natural" el mecanismo adecuado para que la especie mejor dotada evolucione-cambie de una especie en otra, ¿no será más lícito y propio apuntar a una razón o causa intrínseca vital (no meramente dinámica), conjugada con las circunstancias de tiempo y lugar, a la que se debe atribuir esa transformación o evolución de una especie en otra?. El evolucionismo no justifica de dónde viene, ni cómo ni por qué "ese tener mejor condiciones de una especie que otra", o "un individuo mejor dotado que otro en la misma especie" ${ }^{82}$. El pensamiento agusti-

${ }^{79}$ Gen. litt. 3,12,19-20.

${ }^{80}$ Ibíd. 5,5,14; 6,6,10-11.

${ }^{81} \operatorname{Tr}$. 3,9,16: "Aliud est enim ex intimo et summo causarum cardine condere atque administrare creaturam, quod qui facit, solus creator est Deus, aliud autem pro distributis ab illo viribus et facultatibus aliquam operationerm forinsecus admovere, ut tunc vel nunc, sic vel sic exeat quod creatur. Ista quippe originaliter ac primodialiter in quada textura elementorum cuncta iam creata susnt; sed acceptis opportunitatibus prodeunt".

82 ¿Cómo entender que la "selección natural” o "supervivencia del más apto” sea el único mecanismo para que la acción causal y efectora del dinamismo cósmico actúe" (P. Laín Entralgo, o.c. 187 ss.) la evolución de las especies por el simple hecho de que prevalezca "el mejor dotado" debido a sus mejores condiciones o dotaciones que otra de su misma especie? ¿Por qué existen algunos mejor dotados, solo por las condiciones externas de tiempo clima...? Pero, de ahí ¿cómo pasar a afirmar que implique el paso evolutivo-transformismo 
niano, por el contrario, afirma que es debido a una "vis intrínseca natural", "multi-potente" que Dios puso y dispuso en su creación original como causa de toda transformación de una especie en otra, o de una en otras muchas... Porque el hecho de que las razones seminales sean fijas no implica que tenga limitada (fija) su capacidad evolutiva, porque dependen de la capacidad vital que Dios les haya asignada desde el principio. Una misma vis seminal puede evolucionar dando lugar a diversas especies, por su capacidad multi-potente, incluso sobre lo natural (normal) evolutivo, pero nunca contra la naturaleza (ejemplo, los milagros) de naturaleza de su vis pluri-potente creativa. Veamos cómo habla Agustín:

De Civitate Dei (12,5 y 12,25): "Y donde el orden de la naturaleza les exige conservar el ser recibido, mejoran o empeoran..., tendiendo siempre, por providencia divina, al fin que lleva en sí la razón del gobierno del universo". "Una cosa es la especie o forma (species) exterior... "alia vero quae intrinsecus efficientes causas habet de secreto et occulto naturae viventis atque intellegentis arbitrio... dum non fit, facit" 83 ."Sobre este movimiento y curso natural de las cosas, el poder del Creador tiene en sí mismo la facultad de hacer de todas estas cosas otras distintas, cuyo poder viene a ser como la razón seminal para que se haga esto. Sin embargo no hace lo que no colocó en ellas para que de ellas se hiciese, o se pudiera hacer esto por Él" ${ }^{84}$. Así habrá que entender aquel texto De Trinitate: "Laten en los elementos cósmicos ocultas como semillas de todas las cosas existentes que nacen a la vida corporal y visible... El Creador de los gérmenes invisibles es el Hacedor de todas las cosas, y cuanto naciendo tiene existencia visible, bebe su vida, movimiento y grandeza, e incluso, la distinción de sus formas, en estas misteriosas razones seminales regidas por normas perennes y fijas desde su creación primordial" ${ }^{85}$.

Dado la interpretación que se hace de este texto atendiendo "a que las misteriosas razones seminales son regidas por normas fijas y perennes", a muchos autores les ha llevado a decir y deducir la imposibilidad

a otra especie? No se aprecia lógica alguna. Y, en última instancia, ¿cuál es la razón por la cual unos sujetos de una misma especie estén mejor dotados que otros?

${ }^{83}$ Ciu. 12,5; $12,25$.

${ }^{84}$ Gen. litt. 9,17,32: "Horum et talium modorum rationes non tantum in Deo sunt, sed ab illo etiam rebus creatis inditae atque concreatae".

${ }^{85} \operatorname{Tr} .3,8,13$. 
de la evolución de las especies, es decir caer en un fixismo naturalista o providencialista a lo agustiniano. Pero el dato de afirmar que "las razones o vis seminal" son " normas fijas y perennes", para nada impide, sin embargo, que su capacidad goce de "pluri-potencia". Pues de lo contrario no encajaría bien con su concepción de un cosmos en constante dinamismo, por creación: porque Dios siempre trabaja, siempre está creando conjuntamente con sus causas segundas, obviamente no creando ya "ex nihilo", sino haciendo que sus causas segundas sigan haciendo constantemente la aparición de nuevas especies (creación segunda) ${ }^{86}$. Dios creó un mundo lleno de vida y dinamismo que, desde la "nebulosa o materia informe incuba su Espíritu" y lo lleva hacia un "cosmos" que culmina con la aparición del hombre u "homo sapiens-sapiens".

El dinamismo de la "vis causativa originaria" es tal que con la aparición de una nueva especie no desaparece su capacidad para seguir causando nuevas semillas. Para el evolucionismo naturalista, la aparición de una nueva especie debería implicar la desaparición de las menos dotadas, porque de lo contrario ¿qué razón hay para defender que solo permanecen las mejor dotadas? Por eso para el agustinismo no hay una nueva especie "ex nihilo", sino apariciones innumerables de nuevas especies posibles debido a las pluri-potentes causas segundas.

Nuestra tesis ciertamente no se puede contrastar o falsar, cual exigencia popperiana, para garantizar su cientificidad. Pero ¿y la tesis del evolucionismo materialista, "vía selección natural”, acaso sí se puede contrastar? No lo parece en el estado actual de las ciencias. Porque ¿cómo explicar que una especie se trasforma en otra sólo debido a factores externos de la pura materia, por "selección natural", dando a la materia el sentido materialista como algo muerto, exangüe en sí mismo? ¿No luce más convincente y razonable suponer la existencia de una "fuerza-visenérgeia-dínamis" ínsita constitutivamente ya en la "materia-informe" de la naturaleza creada? Pues en todo caso hay que partir del algún previo o "suppositum" razonable. Y que para nosotros, como para Agustín, por tanto, no puede ser otro que la "vis causativa o dinamismo-vital origina-

${ }^{86}$ Gen. litt. 5,20-23; 6,14-17; 8,21-23. Primera creación "ex nihilo". Segunda creación (no ex nihilo) ha de entenderse las constantes apariciones a partir del dinamismo causal (vis seminal) originario. 
rio" de las "razones seminales" 87 . Y que desde luego no parece suficientemente razonable la explicación evolucionista-naturalista.

\section{B. EL DINAMISMO-CÓSMICO SE HACE RAZONABLE DESDE EL DINAMISMO-VITAL ANTROPOLÓGICO}

La tesis del dinamismo cósmico de Pedro Laín Entralgo, se podría enunciar así: "En el principio fue el dinamismo cósmico cuya capacidad "de dar de si" hizo posible la realidad de este mundo (materia-energía) y su proceso evolutivo por la selección natural darwiniana". "La intelección esencial de la realidad del hombre ha de partir de una antropología del dinamismo cósmico ${ }^{88}$, cuya forma de realizarse -el dar de sí- ese dinamismo cósmico se explica por selección natural darwiniana ${ }^{89}$. La selección natural no hay que considerarla, pues, como actividad causal, ni como forma ocasional de una genuina causación, sino como un mecanismo para que la acción causal y efectora del dinamismo cósmico actúe en el nivel de las estructuras vivientes" ${ }^{90}$. El hombre es una estructura viviente evo-

${ }^{87} \operatorname{Tr} .3,8,13-15$ : “....aunque no podemos ver por vista de ojos la virtud germinal, siempre la podemos conjeturar por la razón; pues de no existir en los elementos esta misteriosa virtud, no brotaría en la tierra lo que en ella no se ha sembrado..."; Ibíd.3,9,16: "Una cosa es, desde el íntimo y sublime plinto de las causas, crear y gobernar la criatura, poder privativo del Dios Creador; y otra la acción intrínseca de las fuerzas y energías por Él otorgadas, a fin de que se realice lo que Dios crea, en este o aquel momento, de esta o la otra manera. Todos los seres están originaria y primordialmente contenidos en la urdimbre maravillosa de los elementos y les basta encontrar un ambiente propicio para manifestarse"; Gen. litt. 6,6,9-10: Dios creó todas las naturalezas en sus causas y al mismo tiempo, y todo lo que cotidianamente se opera en el tiempo proceden de aquéllas como primordiales embozos...; porque aquellas cosas que han de ser futuras en los seres están ya incluidas en ellas y, por lo tanto, antes de todas las semillas visibles existen aquellas causas"; Ibíd. 9,15,27-28: La naturaleza sólo ejecuta aquello que por un vigor y movimiento interno, el que a nosotros es ocultísimo"; Ibíd. 6,11,18: Todas las cosas, en un cierto modo han sido incoadas y terminadas. Terminadas porque ciertamente ellas no tienen en sus propias naturalezas, con las que transcurren los cursos de sus tiempos, nada que no haya sido hecho causalmente en ellas. Incoadas, porque eran como ciertas semillas de los seres futuros que habían de aparecer en sus convenientes lugares en el decurso del tiempo saliendo del estado latente al manifiesto".

${ }^{88}$ Pedro Laín Entralgo, o.c. 183 ss.

${ }^{89}$ Ibíd. 187.

${ }^{90}$ Ibíd. 187 ss. 
lutivamente producida por el radical dinamismo del cosmos (natura naturans)" "'La propiedad más esencial del dinamismo cósmico, es dar de sí, potencialidad de vida dentro de sí ${ }^{92}$. "La realidad del cosmos no fue en su origen "materia" y "energía", sino la enigmática realidad que las hizo reales, a la cual, so pena de cosificarla, sólo dinamismo podemos llamar"93.

Esta concepción cósmica (ontológica) no ha de entenderse razonable desde el dinamismo vital antropológico de Agustín, porque en sí mismo, adolece de varias inconsistencias de razonabilidad a la hora de derivar de lo cósmico lo humano-antropológico. Consideremos algunas.

\section{B.1. Varias inconsistencias de razonabilidad del dinamismo cósmico}

\section{B.1.a.- El hombre y la naturaleza como misterio}

Admite que el hombre y su naturaleza son un misterio que la ciencia está lejos de desvelar, y a un tiempo defiende que las modernas ciencias humanas nos desvelan suficientemente el sentido y origen de la actividad humana partiendo del dinamismo originario. Pero so pretexto de este acercamiento se quiere invalidar cualquiera otra contribución razonable, como si el afán científico comprendiera todo el ámbito del conocimiento humano. Que no lo es, como lo demuestra el hecho cierto de que no logra aclarar las tesis antropológicas de la persona-mens. ¿Aclara algo el defender que el universo en su origen "es dinamismo cósmico" y que su constante devenir se explica acudiendo a la "selección natural darwiniana", cuando, al mismo tiempo admite que ésta sólo es un mecanismo para que actúe causal y efectoramente el dinamismo cósmico? Nada explica, porque comete una doble "petitio principii" donde el dinamismo cósmico es su propio dar de sí, y donde la selección natural es un mero mecanismo de actuación, privada de raíz causativa alguna . Entonces ¿dónde está y a qué queda reducido el admitir la "selección natural como base de la evolución"? Nos dirá Rémy Chauvin, que queda reducido a la "famosa trampa dialéctica”, propia de todo evolucionista materialista ${ }^{94}$. Y Francisco José Soler Gil, afirma contundente: "Las deficiencias y disfunciones
${ }^{91}$ Ibíd. 189.
${ }^{92}$ Ibíd. 187.
${ }^{93}$ Ibíd. 185.
${ }^{94}$ Rémy Chauvin, Darwinismo. El fin de un mito, Espasa Calpe, Madrid 2000, 93 ss. 
en toda clase de organismos se pueden multiplicar hasta el infinito, reflejando el carácter oportunista, chapucero, de la selección natural..." ${ }^{95}$. Y todo esto después de confesar, nuestro autor, que la ciencia sólo puede acercarse a las causas o razones penúltimas, nunca a las últimas que son propias de la filosofía. Pero ¿entonces por qué no partir de un razonable Creador de ese dinamismo?

Pero si partir del dinamismo cósmico tuviera base "razonablemente científica”, entonces no tendríamos por qué hacernos la pregunta: ¿el dinamismo cósmico a qué es debido y de dónde procede?. ¿Por qué no se dice cuál es esa base, como sí lo dice el texto bíblico originario cuál es su base razonable? "En el principio Dios creó el cielo y la tierra y su espíritu aleteaba (se cernía) sobre la superficie de las aguas" (Gen.1,1-2), y en concreto, de la tesis agustiniana de las razones seminales. Pero nos preguntamos: "si el fundamento último de la evolución depende del dar de sí del dinamismo cósmico originante", y si "el sentido creacionista agustiniano depende del espíritu vital y dinámico que se cernía en el origen sobre la superficie de las aguas". Entonces no existe razón suficiente alguna para admitir como lo científicamente razonable la tesis del dinamismo cósmico conjuntamente con "la selección natural darwiniana", y rechazar el sentido creacionista dual-evolutivo cristiano-agustiniano.

La diferencia es radical. Y es radical porque parte de un dinamismo originante cósmico como un a priori inevitable-absoluto en sí mismo, sin preguntarse más allá, si ha sido o no creado. Y no entra en consideración, porque -dice- pertenece a la filosofía, a lo creíble. Pero ¿es que no pertenece igualmente a lo creíble partir del dinamismo cósmico? La tesis cristiana afirma que ese dinamismo cósmico (ontológico - antropológico) ha sido creado con su espíritu vital, es decir, donde hay un lugar para el advenimiento de la vida y del hombre. Todo un dinamismo antropológico donde yace inmerso el espíritu humano. ¿Qué razonable razón puede haber para admitir un dinamismo originante indeterminado e indefinido como punto absoluto de partida (causa sui), fundado en la sinrazón suficiente como son el azar y/o la necesidad? Sin embargo, es razonable admitir un principio increado-inteligente, cuya realidad es un agente bien

${ }^{95}$ F.J. Soler Gil, Mitología materialista de la ciencia, Ediciones Encuentro, Madrid $2013,111$. 
definido-concreto, i.e., Dios, como afirma la tesis creacionista cristiana, que lo haga razonable, es decir una "causa incausada, o logos eterno". Entonces ¿no será más razonable decir, de entrada, que obedece al dinamismo de un creador, quien dejó inscritas las razones seminales con intrínseca capacidad causal-evolutiva para originar nuevas especies?

Por lo tanto ¿puede ser una causa incausada el mero dinamismo intrínseco, a partir del cual se explique la explosión originaria" y el consiguiente proceso evolutivo? Absolutamente no, porque ello debe suponer que algo existe para poder explosionar; y que ese algo-alguien previo lo hizo posible (lo creó), y porque además la ciencia se siente incapaz de explicar por qué explosionó de la manera y en el instante en que lo hizo. Cosa muy diferente es hablar del resultado de la explosión, i.e., de su efecto. Así afirma P. Laín Entralgo: "La ciencia de nuestro siglo nos obliga a pensar con convincente razonabilidad que en su origen, en los primeros instantes tras la explosión originaria, la realidad del cosmos no fue "materia" y "energía", sino "la enigmática realidad que las hizo reales, a la cual sólo dinamismo podemos llamar" ${ }^{96}$. Tal afirmación guardaría concordancia fundamental con la expresión bíblica originaria de la creación: "todo era caos y confusión -tohu wabohu-, y el espíritu de Dios aleteaba sobre el abismo..." (Gén. 1,2).

Si esto es lo más razonable, por eso nos venimos haciendo la pregunta radical, que nuestro autor evade, porque según él, pertenece a lo creíblerazonable no a la ciencia de lo racional; pero entonces también pertenece a lo razonable-creíble aceptar un dinamismo cósmico originario, y no a lo racional. Entonces, la ciencia parte de lo razonable, que es propio de las creencias. Pero ¿por qué sus reflexiones, diferenciando lo razonable de lo racional, la ciencia de la creencia ${ }^{97}$-muy pertinente por otra parte-, buscan establecer departamentos estancos entre ciencia y creencia?. Por consiguiente, para justificar su propia tesis debe darnos una respuesta razonable a nuestra pregunta radical: ¿por qué existió el dinamismo cósmico y quién lo causó (o cuál es la causa de su existencia)? Y la respuesta razonable no puede ser otra que la admisión de una causa incausada, de un agente inteligente y creador. Sólo desde esta razonabilidad podemos

\footnotetext{
${ }^{96}$ P. Laín Entralgo, o.c. 185.

${ }^{97}$ Ibíd. 222 ss.
} 
aceptar la racionalidad del dinamismo cósmico, así como su "explosión originaria", o cualquier otro acontecimiento primario sobre el cual la ciencia deba partir para asentar su racionalidad. Si existió la explosión original, es que algo llamado "dinamismo cósmico-antropológico" la hizo posible, y el cual necesariamente tiene un alguien que lo causó (creó)con capacidad explosiva.

\section{B.1.b. El dualismo antropológico.}

Rechaza, por insostenible e "intelectualmente inaceptable", el dualismo antropológico (hilemórfico, cartesiano), cuyos componentes "almacuerpo" se mantienen como realidades distintas y externas entre sí, para negar toda influencia posible del alma, realidad espiritual (inmaterial y extra-corporal) sobre el cuerpo, realidad material, porque "solo cabría si de un ente omnipotente se tratara" 98 . Para nada considera el dualismo moderado o la dualidad antropológica.

Razones estrictamente intelectuales, tanto de orden gnoseológico como genético, me impiden, dice P. Laín Entralgo, admitir en modo alguno el dualismo antropológico, sea hilemórfico o cartesiano. De orden gnoseológico: el hilemorfismo escolástico explica la conversión de las "especies sensibles" en "especies inteligibles", por la acción directa y transformadora del alma espiritual sobre la materia del cuerpo. Es imposible, dice, atribuir razonablemente tal acción transformadora a un espíritu finito y no omnipotente como el alma humana ${ }^{99}$. De orden genético: Los dualistas actuales rechazan abiertamente que los mutantes humanos de homínidos, pudieran formarse naturalmente sin previa infusión en su materia de un alma espiritual. ¿Acaso la embrio-génesis actual no obliga a decir que el óvulo fecundado no pasa de ser "hombre en potencia condicionada"; "condicionada a la inexistencia de una adecuada intervención del experimentador"? ${ }^{100}$.

Rechazamos también nosotros todo dualismo antropológico; sin embargo, no encontramos justificadas las críticas interpretativas de Pedro Laín E., en línea de Zubiri, ni en línea agustiniana.

No justificadas en 'el orden gnoseológico', porque ciertamente no es admisible que las actividades del compuesto "alma-cuerpo" sean mutua-

\footnotetext{
${ }^{98}$ Ibíd. 178 ss.

${ }^{99}$ Ibíd. 180.

${ }^{100}$ Ibíd. 181 ss.
} 
mente externas. Pero tampoco es aceptable la contundente afirmación de P. Laín Entralgo: "la actividad del alma sobre el cuerpo, ella sólo es posible si de un ente omnipotente se tratara". Dicha afirmación prueba demasiado y quien prueba demasiado "nihil probat". Y ello por un doble motivo: porque el hecho real constata una mutua e intrínseca relación, ya que no se trata de dos realidades o substancias separadas y mutuamente externas, sino de una y misma substancia-substantividad (realidad) o unidad dual ${ }^{101}$, y porque "el alma espiritual (racional), aunque mudable y finita participa de la inmutabilidad misma de la Sabiduría"102. Habrá que admitir, entonces, en fuerza de la lógica, dentro de una antropología integradora y jerarquizada como la agustiniana, la influencia del alma-espíritu sobre el cuerpo, lo superior sobre lo inferior, lo espiritual sobre lo corporal, lo psíquico sobre lo orgánico ${ }^{103}$, que aquí es dominancia. "El alma que no tiene naturaleza corporal..., sino que está unida de modo maravilloso al cuerpo que vivifica por la misma incorpórea voluntad en virtud de la cual ejerce su imperio en el cuerpo por cierta determinación interna"104. Pero, admitida porque es real la influencia presencial de lo sensible y corporal en el alma -el alma siente en el cuerpo y a través del cuerpo (sensación) ${ }^{105}-$, sin embargo, no se ha de creer que el cuerpo obra algo en el espíritu, como si el espíritu se sometiera a la condición de la materia"106 (aquí no hay dominancia).

${ }^{101}$ Conf. 8,21: “...no somos una mezcolanza de dos naturalezas oriundas de principios contrarios, sino división de una naturaleza contra sí misma...". "En su esencia, cuerpo y alma constituyen una realidad única, el hombre en su identidad de persona. "Buena parte de la actividad desarrollada por el alma depende de las funciones del cuerpo, "al hombre interior, a la mens es a quien comunican sus noticias todos los mensajeros corporales, como a presidente y juez... El hombre interior es quien conoce estas cosas por ministerio del exterior; yo interior conozco estas cosas; yo mens por medio del sentido del cuerpo" (Conf. 10,6,9); cf. A. Pieretti, a.c., 366; X. Zubiri, Sobre el hombre, 48 ss.

102 Tr. 3, 2-3.

${ }^{103}$ An. quant. 33, y 35: "Influencia-potencia del alma (mens) sobre el cuerpo"; cf. X. Zubiri, Sobre el hombre, 81 ss.: "La diversidad de acción en la integridad de las notas es formalmente una "dominancia" de unas notas sobre otras en la acción del sistema entero... dominancia que puede estar del lado de la inteligencia o del sentimiento"; Ibíd. 494; 506.

104 Gen. litt. 8,21,42.

105 An. quant. 30,58.

${ }^{106}$ Ibíd.12,16,33. Porque cosa muy distinta es que influya, y otra que el cuerpo obre algo en el espíritu, porque como ha dicho en otros textos es el espíritu quien obra y quien siente en el cuerpo. Influye el cuerpo en el alma, en cuanto que le presenta los elementos o condiciones materiales sobre los cuales opera la dinámica espiritual. 
No justificadas tampoco en 'el orden genético', porque su posición que no puede negar la condición humana del feto desde el instante de la concepción, con independencia de cualquier intervención del experimentador. Por el contrario, el sentido de ese feto-hombre "no en acto", pero sí en potencia pasiva, es ya "en germen" un ser humano, formalmente y no sólo virtualmente hombre" (Zubiri) ${ }^{107}$. Para Agustín el feto-germen humano vivificado, precisamente por ser humano, es inaceptable su manipulación. He aquí el modo de expresarse que al respecto tiene Agustín, ya en aquel tiempo: "Al bebé (infante, recién nacido) le falta ciertamente la perfección de la dimensión corporal, pero ha de poseer lo que le falta. Esta clase de perfección de tal manera la tienen todos, que con ella son concebidos y nacen. Pero la tienen en exigencia virtual, no en la cuantidad, como los miembros están todos latentes en el germen. Esta exigencia de cada uno, impresa en la materia corporal, ya parece, en cierto modo, iniciado lo que todavía no existe, aún más, lo que está oculto, pero que con el tiempo existirá, o más bien aparecerá. En esta exigencia, pues, el bebé que será un día grande o pequeño, lo es ya al presente"108. Se comete un acto criminal "matar en el seno materno el feto concebido" porque todo está anticipado en la semilla, en el germen vital ${ }^{109}$. Y así se expresa X. Zubiri, y precisamente en línea agustiniana, según queda ya referido : "Todo lo que el hombre es, está ya embrionariamente en el punto de partida y por tanto, en él hay ya psique..." ${ }^{110}$.

Pero -nos preguntamos nosotros- ¿por qué no hablar del dualismo moderado? ¿Por qué no atender a la concepción dual del hombre, i.e., a la dualidad antropológica, donde la unión de dos coprincipios, cuerpo y

${ }^{107}$ SH 48-49; 488 ss.; 164: "en el plasma germinal está ya la psique con su inteligencia..."; Ibíd. 490; 494.

108 Ciu. 22,14; Gen. litt, 3,14,23.

${ }^{109}$ Nupt. et conc. 1,15,17: "Los que abandonan a los niños nacidos y no deseados, cometen un acto cruel, y llega al summum su crueldad, cuando emplean drogas esterilizantes, y, si estas no son eficaces, matan en el seno materno el feto concebido y lo arrojan fuera...". En aquella semilla tan pequeña, apenas visible, - si aplicas la inteligencia y no la vista- se oculta también la raíz; dentro de ella está el tronco y las hojas futuras y el fruto que aparecerá en el árbol. Todo está anticipado en la semilla” (S.347,2; cf. Qu. 2,80; cf. Tarsicio Jáñez, “Argumentación deóntica versus legitimación del aborto", Lógoi 8, UCAB, Caracas 2005, 99-118).

${ }^{110} \mathrm{SH} 463 ; 49-50 ; 496$ ss. 
alma, constituyen una sola realidad que implica la vida humana, cual sentido razonable del alma-mens, y donde las relaciones o influencias entre alma y cuerpo pertenecen a la unidad del compuesto imperado por la "alma-mens"? Recuerda Agustín que "mediante el cuerpo siente y conoce el alma las realidades sensibles, siendo el alma su juez y árbitro"111. Aquí en la dualidad antropológica, configurada como realidad integradora, cabe ubicar la concepción de Agustín. Lo apreciamos particularmente en la concepción agustiniana de la sensación y en todo el proceso del conocimiento. Si P. Laín Entralgo hubiera aclarado que aquel dinamismo cósmico llevara consigo el vitalismo humano (mens-inteligencia), que incluyera la unidad antropológica dual, solo entonces estaría razonablemente justificado el rechazar todo dualismo y el omitir la concepción antropológica dual ${ }^{112}$. He aquí por qué $\mathrm{X}$. Zubiri en concordancia fundamental con Agustín, afirma que en ese dinamismo cósmico ha de operar una nueva causalidad distinta, exigitiva y efectora, que haga posible el advenimiento del alma humana (inteligencia-mens): "Rigurosamente hablando el dinamismo cósmico del Todo (natura naturans) deberá ejercer un acto de causalidad distinta para producir una inteligencia (mens); una causalidad distinta de la que ha producido para vitalizar la materia y cada uno de sus grados evolutivos. Y esta causalidad es causalidad efectora y no meramente exigitiva. Y el Todo precisamente ejercita una causalidad efectora en la producción de las inteligencias y del psiquismo humano"113. Bien precisa Ilya Prigogine: "La dinámica -el dinamismo cósmico- sólo nos proporciona las condiciones necesarias para la inteligibilidad de los modos de evolución,... mas no suficientes, de surgimiento de una autoorganización adecuada para la vida" ${ }^{114}$. ¿Por qué, entonces no partir del dinamismo de un Todo cósmico-antropológico, como por ejemplo las razones seminales causales agustinianas?

Nuestro autor, en su crítica al dualismo antropológico, niega sin paliativos la posibilidad misma de una influencia del alma sobre el cuerpo,

${ }^{111}$ Conf. 10,6,9; cf. A. Pieretti, a.c. 363.

112 Stephen J. Duffy, a.c., 87. Pero no se entiende por qué afirma más adelante que a Agustín "le obsesionaba un dualismo existencial" (Ibíd.94), a no ser que se diga referido a la dramática lucha interior.

113 EDR 214 ss.

114 Ilya Prigogine, o.c. 141. 
lo cual implica negarla también dentro de una concepción antropológica dual. "Quod est probandum". Pero ¿acaso le es también aplicable al dualismo moderado, o dualidad antropológica, el defender que los constituyentes "alma-cuerpo" son realidades mutuamente externas-separadas? Para la dualidad antropológica es un hecho vivencial las mutuas influencias dentro de la unidad integral de un todo-aunque en diversa intensidad o grado- ${ }^{115}$. Porque ¿quién le ha dicho a nuestro autor y de dónde saca el argumento para afirmar de modo tan rotundo que "la influencia de lo espiritual en lo corporal sólo es posible si de un ente espiritual-omnipotente se tratara"? Pues, de no admitir siquiera la posibilidad de las influencias de lo espiritual en lo corporal, con cuánta mayor razón no tendríamos que negar toda influencia del mundo material sobre el alma espiritual, i.e., sobre la realidad mental de la persona. ¿Es que la ciencia antropológica moderna y la psicología profunda no gozan de suficiente experiencia y hasta evidencia de la influencia de lo espiritual-mental sobre lo corporal y material ${ }^{116}$ ¿ ¿Es que antropologías duales como la agustiniana, no parten razonablemente de que el alma-espíritu humano es partícipe de la Sabiduría divina, según hemos consignado más arriba? Es más, el hombre tiene corporeidad porque tiene "mens", y no a la inversa. "El hombre tiene manos porque piensa, porque tiene "nous - mens" (Aristóteles) ${ }^{117}$. El cuerpo humano sólo se configura existente por el alma, no a la inversa. "El cuerpo-humano subsiste por el alma-mens; mediante ella (el alma) recibe su ser el cuerpo) (S. Agustín) ${ }^{118}$. Aquí no se puede negar la influencia de la mens-alma en el cuerpo que es constitutivo de la unidad de un todo. Una antropología jerarquizada, la experiencia misma lo está pi-

${ }^{115}$ Esta relación se hace dualidad dramática -hasta podríamos llamarla dualismo del alma contra el alma misma- en la lucha moral establecida entre el hombre viejo y el nuevo, siendo, sin embargo, una sola el alma que lucha contra sí misma, como si de dos voluntades distintas se tratara :"Con todo, no obraba, y más fácilmente obedecía el cuerpo al más tenue mandato del alma de que moviese a voluntad sus miembros, que no el alma a sí misma para realizar su voluntad grande en sola la voluntad... Manda el alma al cuerpo y le obedece al punto; mándase el alma a sí misma y se resiste..." (Conf. 8, 8,20 y 8,9,21). Se trata de la lucha de la carne contra el espíritu... "estando yo realmente en ambos..." (Ibíd. 8,5,11).

${ }^{116}$ Cf. Viktor Emil Frankl, La presencia ignorada de Dios. Psicoterapia y religión, Herder, Barcelona 1984, 21 ss.

${ }^{117}$ Mariano Artigas-Daniel Turbón, Origen del hombre. Ciencia, Filosofía y Religión, Eunsa, Pamplona 2008, 128; 135 ss.

${ }^{118}$ Inm. an. 15-16; De cont. 8,21; Ord. 2,6,19; Gen. litt. 8,21,42; Tr. 8,6,9. 
diendo desde un proceso integrador, la subordinación de lo inferior a lo superior, de lo material-corporal a lo espiritual-mental.

\section{b.1.c. El mentalismo}

No acepta el mentalismo, y tampoco nosotros, aunque por diverso motivo; porque, según se expresa Pedro Laín Entralgo, "los seguidores del este movimiento se resisten a plantearse científica y filosóficamente el problema de lo que realmente es el agente de los actos mentales a tenor de las investigaciones neurofisiológicas y de la psicología comparada"; porque, dicen, "que es imposible reducir su explicación a los recursos de estas dos ciencias" 119 ; $\mathrm{y}$ "no se deciden a aceptar la realidad de un principio inmaterial contra-distinto del cuerpo como lo hace el dualismo metafísico" 120 . Dado que la corriente mentalista afirma que los actos mentales se explican suficientemente desde la actividad psíquica, sin atender a quién es realmente el agente de los actos mentales, y dado también que, según la tesis de Pedro Laín Entralgo, estos actos mentales sí explican científicamente quién es realmente el agente de los actos mentales, sin acudir a agente espiritual distinto, nos impide aceptar, por igual, aunque por diverso motivo, tanto este tipo de mentalismo, como la tesis de P. Laín Entralgo: "La condición mental de un acto es una apariencia subjetiva o un epifenómeno de un acto puramente cerebral" 121 . La tesis agustiniana, por el contrario, afirma conjuntamente una triple relación real de la "mens": que los actos humanos todavía no son debidamente explicados por las ciencias, porque el hombre sigue siendo "magnum mysterium" 122 ; que la mens -memoriaentendimiento-amor (voluntad) - es sujeto y causa directa de toda la actividad humana, libre y responsable ${ }^{123}$, y, finalmente, que el principio inmaterial (incorpóreo)-espíritu contra-distinto del cuerpo es constituyente integrador de la "mens". En fin, esta triple realidad relacional está afincada en la "mens" por ser "imago Dei trinitatis". El hecho de que la "mens-persona", sea causa directa y sujeto de sus acciones, para nada impide que la causa última y suprema sea la voluntad de Dios Creador-Providente: "En Él somos, nos movemos y existimos" (S. Pablo).

\footnotetext{
${ }^{119}$ P. Laín Entralgo, o.c., 183.

${ }^{120}$ Ibíd. 177.

${ }^{121}$ Ibíd. 178.

122 Conf. 4,14, 22: “Grande profundum est ipse homo..."; 10,17,26; S. 110,2.

${ }^{123}$ Lib. arb. 3,17,49; Ciu. 5, 9,3; 14,3,1-2.
} 


\section{B.2. Resaltemos tres críticas sobre tres considerandos de P. Laín Entralgo}

Desde las anteriores críticas, queremos resaltar, ahora en particular, como no aceptables, otras tres de las afirmaciones de P. Laín Entralgo: La primera, "los términos paulinos, sarx, psykhé (alma) y pneuma, no son principios constitutivos de la realidad viviente del hombre, sino modos de comportamiento" 124; la segunda, "la acción-relación mutua entre alma y cuerpo propia de todo dualismo", son relaciones de exterioridad y donde lo espiritual (alma) no tiene capacidad de influencia en lo corporal: es un epifenómeno de un acto puramente cerebral ${ }^{125}$; $y$ la tercera, "no es preciso admitir la existencia de un alma espiritual-mental para explicar que el hombre es imagen y semejanza de Dios y ser constitutivamente libre" 126 .

Contestamos: A la primera, "no es ese el sentido que estos términos tienen en S. Pablo, ni es la interpretación de los exégetas bíblicos, ni de la Iglesia Católica en su Nuevo Catecismo ${ }^{127}$ y añadimos además que sí son principios (co-principios) constitutivos, conformando una sola realidad entitativa, y donde el alma es principio vital constituyente, de tal manera que sólo por el alma-mens el cuerpo existe como humano ${ }^{128}$. "El alma significa el principio espiritual en el hombre", afirma el Nuevo Catecismo de la Iglesia Católica' ${ }^{129}$. A la segunda, no son relaciones de exterioridad, porque alma y cuerpo forman una unidad personal intrínseca ${ }^{130}$, pues el alma-mens subsume cabe sí la realidad corporal ${ }^{131}$, al modo de la unión

${ }^{124}$ P. Laín Entralgo, o.c. 230.

${ }^{125}$ Ibíd. $178 ; 180 ; 230$ ss.

126 Ibíd. 230.

${ }^{127}$ CCE, Nros. 356 ss.; cf. José Antonio Sayés, Teología y relativismo. Análisis de una crisis de fe, BAC, Madrid 2012, 197 ss.

${ }^{128}$ Inm. an. 15,24: "El cuerpo en tanto es, en cuanto es animado... mediante el alma recibe su ser el cuerpo" (Ibíd. 16,25); Ord.2,6,19: "Comprendo que no puede haber un organismo vivo sin su alma”. El alma da al cuerpo la forma. i.e., la especie de cuerpo humano (Lope Cilleruelo). (Gen. litt. 8,21,42; Tr. 8,6,9).

${ }^{129}$ CCE, Nros. 362 y 363.

${ }^{130} \operatorname{Tr} .11,4,7$ : “...unidad integrada..., porque todo esto es interior y todo es un alma”; Gen. litt. 3,16,25: el alma es una fuerza grande y admirable, la cual sostiene vitalmente en unión inefable aquella constitución de su ser...”; Ibíd. 8,21,42: “Como el alma no es de naturaleza corporal, ... sino que está unida de modo maravilloso al cuerpo que vivifica, por la misma incorpórea voluntad, en virtud de la cual ejerce su imperio en el cuerpo, mas no por la fuerza de una masa corporal".

${ }^{131}$ Gen. litt. 8,21,42;12,16,33; 12,23,49. 
hipostática ${ }^{132}$. Y a la tercera, es necesario, de toda necesidad, admitir que el alma humana sea espiritual por ser "a imagen y semejanza de Dios". Y lo es por creación. Además no puede afirmar que "el hombre es imagen de Dios propiamente por ser hombre libre", sino a la inversa, por ser imagen de Dios es libre. Y lo es, también por creación. De otro modo ¿cómo explicar que el alma-mens sea imagen de Dios y no sea espiritual? Pero ahora, hablando con la precisión y densidad que habla Agustín, y que reclama el sentido bíblico mismo, el hombre es imagen y semejanza del Dios trino, sólo en tanto es mens-persona, no en cuanto a la totalidad de su constitución humana: "He aquí por qué cada hombre individual es imagen de Dios sólo según la mente, no según toda la amplitud de su naturaleza, y es una persona y en su mente está la imagen de la Trinidad"133.

\section{EL DINAMISMO VITAL-EVOLUTIVO CULMINA EN LA MENS- PERSONA}

En estas posiciones que venimos criticando -el monismo materialista por supuesto-, tanto dualista, mentalista, como la de P. Laín Entralgo, entendemos que hay un doble error de base: suponer que el alma es algo exterior a la persona y que el cerebro es causa única de las diversas acciones. La unidad dual, por el contrario, clama constantemente por defender la unidad del compuesto en su doble dimensión unitaria: donde el "almamens", desde su base cerebral rige y dirige toda actividad de carácter bien bilógico-orgánico, bien espiritural-mental, y desde donde a su vez la "mens-persona" está intrínsecamente constituida por una doble dimensión inmanente y trascendente, efecto del mismo hecho creador ${ }^{134}, \mathrm{y}$ cuyo

${ }^{132}$ Ep. 137,3,11; cf. Lope Cilleruelo: 3,2; Stephen J. Duffy, a.c. 86 ss.; Antonio Pieretti, a.c., $363 \mathrm{ss}$.

${ }^{133} \operatorname{Tr}$. 15,7,11: "Quapropter singulus quisque homo, qui non secundum omnia quae ad naturam pertinens eius, sed secundum solam mentem imago Dei dicitur, una persona est, et imago est Trinitatis in mente"; cf. $\operatorname{Tr} 14,8,11$ : "la imagen de Dios hay que buscarla en la parte más noble de nuestra naturaleza” (Ibíd. 15,3,5; 12,4,4; 12,7,12); Ibíd.14,12,16 : “... es la mente humana hecha a imagen de su creador"; Ibíd.14,16,22: "Toda mente es espíritu, pero no todo espíritu es mente,... La renovación ha lugar en la imagen de Dios, i.e, en la mente"; Ibíd. 15 23,43: "La mente con estas tres facultades (haec tria: memoria,inteligencia y voluntad) es una persona" (Ibíd. 9,3-6; 6,9,10).

${ }_{134}$ S. 30,4: "Uno sólo es el autor de la mente y del cuerpo. Cuando creó Dios al hombre hizo una y otra cosa, y a ambas juntó en unidad". "El alma es el principio de todas las 
dinamismo antropológico evolutivo encuentra explicación suficiente en las "rationes seminales-causales" agustinianas.

Dios al crear el mundo todo lo dispuso según un orden jerárquico de infinita variedad y hermosura ${ }^{135}$, y donde la persona-mens ocupa la cima hacia la que tiende y en la que culmina toda la creación: el mundo (universo-tohu wabohu) se va haciendo "cosmos" y el hombre "su micro-cosmos" ${ }^{136}$. Este orden jerárquico pide que la unidad dual del hombre esté constituida por la dominancia de la "mens" sobre el cuerpo ${ }^{137}$ y sobre los seres de la naturaleza. "Fuimos creados a imagen de Dios según la mens, y por eso la Escritura narra que no sólo fuimos antepuestos, sino también puestos al frente de las bestias, reptiles, aves, peces y toda la tierra, i.e., que nos están sometidos"138.

Por eso la tesis agustiniana entiende y admite que la "mens-persona", es agente y centro integrador de toda actividad humana material y espiritual. Dentro de una concepción antropológica integradora y jerarquizada, la influencia más directa y propia corresponde a lo mental-espiritual (alma-vida, dinamismo vital) sobre el mundo material; y esto por una razón obvia, lo superior y mejor ha de tener dominancia sobre lo inferior y material ${ }^{139}$; "y que lo más noble que hay en tu persona (mens) impere sobre lo inferior. Lo más noble y mejor que posees es aquello en que reside la imagen de Dios, i.e., la mente o inteligencia" ${ }^{140}$. Lo exige el principio de buena ordenación. Y no parece que la ciencia moderna esté en condiciones de negar dicha influencia, ni dicho principio.

Así mismo, entendemos que ni la concepción de la corriente mentalista expuesta por P. Laín Entralgo ni su propia concepción del cerebro explican medianamente la compleja función causal que desarrolla la dinámica de la persona y que, por el contrario, está muy puesta en razón la

\footnotetext{
operaciones del hombre (An. et or. 4,6,7); "Es el sujeto último de las sensaciones" (An. quant. 22,38; Sol.2,4,6).

135 Cf. V. Capánaga, “Introducción General”, en: Obras completas de San Agustín Vol. I, BAC, Madrid 1989, III,46 ss.

${ }^{136}$ Conf. 1,1,1.

${ }^{137}$ Gen. litt., 8,21,42; Ibíd. 8,23,44; An. quant. 14,23;33,70.

138 Conf. 13. 23,34; S. 43,3.

139 Así también considera la dominancia X. Zubiri: Sobre el hombre $81 \mathrm{ss;} 506$.

140 S. 53,A,12.
} 
concepción agustiniana de "mens-persona", creada "ad imaginem Dei Trinitatis"141, porque con su dinamismo interior subjetivo y superior trascendente o interioridad trascendida ${ }^{142} \mathrm{y}$ asentada sobre la base imprescindible de la intrínseca función cerebral o causa material ${ }^{143}$, se constituye en verdadero sujeto-agente, causa formal, directa e inmediata, de cuantos actos realiza la persona: sensitivos, intelectivos, volitivos, tanto conscientes como pre-conscientes. "El alma distinta del cerebro, se sirve de él como de un instrumento, vivificando y rigiendo todas sus operaciones. El cerebro es el centro operativo donde reside la memoria (mens) ${ }^{144}$; "el alma se apoya en el cerebro...", órgano necesario -mas no suficientepara que pueda darse la sensación... ${ }^{145}$. "Nuestro cuerpo está animado por un alma racional que, aunque mudable, participa de la inmutabilidad misma de la Sabiduría"...; "la orden proviene del alma y se transmite al cuerpo que gobierna, pero la causa primera-suprema proviene de la voluntad invisible e inconmutable de Dios, que actúa por medio del almamens..." ${ }^{146}$, respetando su libertad.

Precisamente por eso, también "nuestras voluntades están en el orden de las causas"... "quoniam et humanae voluntates humanorum operum causae sunt" 147 . Pues la misma voluntad de Dios ha querido que la persona-mens sea el sujeto causa inmediata y directa de todo mi obrar responsable ${ }^{148}$. "Cuando yo deliberaba, yo era el que quería y el que no quería yo era; cuando uno delibera, una sola es el alma-mens, agitada por

$141 \operatorname{Tr} .15,7,11$.

${ }^{142}$ Conf. 3,6,11: "Deus interior intimo meo, et superior summo meo"; Ibíd. 4,12,18: "iintimus cordi est”; Ibíd. 1,2,2: "Yo no sería en modo alguno si no estuviese en Ti”; Ibíd. 10,26,37: “¿... dónde Te hallé, pues, para conocerte, sino en Ti sobre mí? ... Al decir 'Dios' decimos el quien originante de todo... que está por detrás, por delante y por encima de aquel todo al que todos pertenecemos" (K. Rahner); cf. Manuel Cabada Castro, o.c. 84.). Al hablar de "transcendencia" nos referimos a quien es inmanente al mundo y trascendente a y en el mundo" (X. Zubiri). (X. Zubiri, Sobre el hombre, 24 ss.; 37-38; 59-60).

${ }^{143}$ Agustín lo llama sensación, cf. An. quant. 30,58 y 59.

144 Gen. litt. 7,17,24.

145 Ibíd. 12,20,42-43.

$146 \operatorname{Tr} .3,2,8$, y $3,3,8 ; 3,4,9$.

147 Ciu. 5,9,3.

148 "La causa del pecado tiene su origen en el alma..." (Ibíd.14, 3,1-2); "El origen de la rectitud o malicia depende de la voluntad humana" (Ibíd. 14,6; 12, 7-8); "La voluntad es la primera causa del pecado" (Lib. arb. 3,17,47-49). 
diversas voluntades (quereres)"149. "Aquí el poder es lo mismo que el querer, y el querer era ya obrar" 150 ."El movimiento es mío, y la resistencia por la que no consiento también lo es... Quiero estar sano todo entero, pues que todo soy yo..."151. "Dentro de mi mens encontré tres cosas: memoriainteligencia-voluntad, que se manifiestan separadamente y obran inseparablemente, y que el nombre de cada una de ellas ha sido obra de las tres"152. "Y las tres son unidad"153. "Notamos ya la presencia de la mente en la memoria, en la inteligencia y en la voluntad...; bien es cierto que no siempre se cree distinta de aquellas cosas que no son lo que es ella, y por esto hay dificultad en distinguir en ella la memoria, la inteligencia y la voluntad. Semejaba como si no fueran facultades distintas sino una expresada con nombres distintos... ${ }^{154}$."Yo recuerdo, comprendo y amo sirviéndome de mis tres facultades (haec tria)... Estas tres facultades son mías, no suyas; constituyen la mens (aunque no son toda la mens), y cuando obran (actúan), soy yo el que por medio de ellas actúo (obro)... Soy yo el que conozco..., y cuando pienso, descubro en mi memoria que comprendo y amo... y por estas facultades soy yo quien entiendo, recuerdo y amo... Si en el hombre consideramos su mens, su conocimiento y su amor -o su memoria, inteligencia y voluntad- ninguna parte de la mens recordamos si no es por la memoria, ni comprendemos sino por la inteligencia, ni amamos sino por la voluntad"155.

En fin, la "persona-mens", que "soy yo mismo", centro de unidad constitutiva, es quien ejerce las funciones de verdadero sujeto agente con su dualidad (sui et Dei) de triple y trinitaria relación unitaria: "memoria sui et Dei; intellectus sui et Dei; amor-voluntas sui et Dei"156. Esta funda-

${ }^{149}$ Conf. 8, 10,22; 8,5,10-11.

${ }^{150}$ Ibíd. 8,8,20.

${ }^{151}$ S. 30,4.

152 Ibíd. 52,18-23.

${ }^{153} \operatorname{Tr}$.10,11,17-18. "La mente reconoce en sí misma con toda certeza estas cosas: memoria, inteligencia y voluntad (amor)... Son tres según sus relaciones recíprocas... Y cuando todas y cada una se comprenden, existe igualdad entre el todo y la parte; las tres son unidad...".

${ }^{154}$ Ibíd. 10, 12,19.

155 Ibíd. 15,7,12; cf. Ibíd. 12,2-4: "ratio sui et ratio Dei (ratio minor et maior)"; 14,4,6; Io. eu. tr. 15,$19 ;$ S. 43,3$)$.

${ }^{156}$ Tr. 14,6,8-9; 14,11,14; 10,3-4; 10,10-11; 14,8,1; 15,3-7; Conf. 10,8,12-14. Cf. Lope Cilleruelo, "La memoria sui", en: Giornale di Metafisica 9 (1954) 478-492; Id., "La memoria Dei según San Agustín”, en: Augustinus Magister, Paris I (1954) 499-509; A. Pieretti, a.c. 350 
mentación antropológica se nos presenta como la tesis más razonable para vislumbrar el misterio del hombre-persona (mens), cuyo dinamismo vital nunca es mono-causal, ni mono-polar, sino que, por el contrario, obedece a una pluralidad de motivaciones causales en sus diversos niveles de causación, pero orquestado desde su centro causal de referencia: mens-persona "imago Dei Trinitatis", culmen y perfección de todo el proceso creador-evolutivo.

ss; José A. Galindo Rodrigo, "Desde el hombre a Dios con San Agustín”, en: Pensamiento Agustiniano 3 (1988) 94 ss. UCAB, Caracas; Id., “Teoría del conocimiento”, en: PAHH-I 425 ss. 